\title{
Analysis of Stress Backlogs during Case-File Processing in Forensic Science Laboratory
}

\author{
Gloria Cuthbert Omari'1, Samwel Victor Manyele², George Mwaluko \\ ${ }^{1}$ Department of Mechanical and Industrial Engineering, University of Dar es Salaam, \\ Dar es Salaam, Tanzania \\ ${ }^{2}$ Government Chemist Laboratory Authority, Dar es Salaam, Tanzania \\ Email: gcla@gcla.go.tz, sammanyele@gmail.com
}

How to cite this paper: Omari, G.C., Manyele, S.V. and Mwaluko, G. (2017) Analysis of Stress Backlogs during Case-File Processing in Forensic Science Laboratory. Engineering, 9, 1060-1096. https://doi.org/10.4236/eng.2017.912063

Received: November 15, 2017

Accepted: December 26, 2017

Published: December 29, 2017

Copyright (C) 2017 by authors and Scientific Research Publishing Inc. This work is licensed under the Creative Commons Attribution International License (CC BY 4.0).

http://creativecommons.org/licenses/by/4.0/ (c) (i) Open Access

\begin{abstract}
Case-file backlogs were identified as one of the cause factors affecting the competitiveness of the forensic science laboratory (FSL). Backlogs represent case-files that remain unprocessed or unreported within a selected time interval (year, week or month) which leads to increased customer complaints, rework, cost of analysis, degradation of biological samples, etc. Case-file backlogging was quantified in three consecutive years (2014 to 2016), using the following parameters: case-files received and case-files processed, difference of which gives case-files backlogged. There was a need to define time interval for a case-file to be regarded as backlogged (that is, one week), results of which can translate into backlogged case-files per month or year. A data collection tool was established and used for three work stations (forensic chemistry, biology/DNA and toxicology laboratories). The tool includes starting and ending date for each time interval, in which the numbers of case-files received and processed were entered followed by computing the backlogs. It was observed that, case-files reported increased between 2014 and 2016 leading to a decrease in backlogged case-files. The annual percentage of the case-files backlogged was highest for forensic toxicology. The highest number of case-files backlogged was observed for forensic chemistry, followed by forensic biology/DNA. The number of case-files backlogged per analyst per year was highest in 2014 and dropped continuously towards 2016, being comparably higher in forensic biology/DNA and chemistry. Probability density functions (PDFs) and cumulative distribution functions (CDFs) of backlogs data indicated that a large number of backlogs created in previous weeks were eliminated. It was concluded that the effect of case-file backlogging on FSL competitiveness can be minimized by continued management effort in backlog elimination.
\end{abstract}




\section{Keywords}

Forensic Science Laboratory, Case-File Processing, Backlogs, Forensic Chemistry, Forensic Toxicology, Forensic Biology/DNA, Case-File Influx

\section{Introduction}

The word forensic comes from the Latin word forensis which implies public, to the forum or public discussion; argumentative, rhetorical, belonging to debate or discussion. Thus, Forensic Science relates to fact-finding through use of scientific methods, and the application of those facts to laws or in a court of law. Criminal investigation is an ancient science that may have roots as far back as 1700 BC. When a serious crime is investigated, the investigation process typically consists of four steps: physical evidence is collected at the crime scene by police officers or crime scene investigators; the physical evidence is analyzed by forensic scientists (often chemists) in a laboratory; all the evidence (that means the analyzed physical evidence and other evidence like eye witness stories, police reports, crime scene sketches and interrogation, etc.) is interpreted by detectives; and evidence is presented in court.

In Tanzania, forensic sciences are used around the country to resolve civil disputes, to justly enforce criminal laws and to protect public. There is one main forensic science laboratory in Tanzania, publicly owned and specializing in forensic toxicology, chemistry and biology/DNA. Forensic scientists are always involved when unbiased, objective and scientific analysis is needed to find the truth and to seek justice in a legal or civil proceeding. A forensic science laboratory is a common term for a facility where personnel process evidence using scientific methodology (more often related to crimes and crime scenes). The evidence processing and analysis in a forensic science laboratory include DNA, blood alcohol, blood and urine drug analysis, drug of abuse analysis and chemicals generically referred to as controlled substances, explosive evidence analysis, toxicological analysis, arson and many other areas. Drugs of abuse or controlled substance identification are the analysis performed in the largest percentage in the Tanzanian FSL. In most countries, like Tanzania, FSLs are a critical component of criminal investigations and the administration of justice, which are publicly funded. The FSL examine and report on physical evidence in criminal matters and also provide court testimony or expert witness regarding that evidence. The FSLs receive requests for forensic services from a variety of sources, including the police, other law enforcement officials, medical examiners, advocates and correctional facilities. The critical problem facing most FSLs is workload, leading to high backlogs, analysis of which forms the main focus of this study.

In this paper, different methods for measuring workload, such as number of case-files or requests received have been utilized to establish the current state of backlogs in the FSL. A case-file is defined as evidence submitted to a forensic science 
laboratory from a single criminal incident, which may require more than one request for forensic science services but may also involve a large number of samples or exhibits that require laboratory analysis. For instance, a laboratory may receive samples of stained clothes; specie remains and fresh blood (splatter) from the same case that requires analysis by different disciplines of the FSL. This study examined workload in terms of both case-files received and reported. The main problem addressed in this paper is large extent backlogs in the different forensic science disciplines.

Greatest personnel need is based on the largest number of backlogged case-files or samples. The ability to process a larger percentage of evidence depends on numerous factors including the complexity of the procedures, use of innovative solutions, and availability of competent, skilled and experienced analysts and other resources. When laboratories are unable to complete all outstanding requests, the remaining requests are backlogged. The completion rate will be lower for more complex types of analysis, such as DNA analysis and biology screening. Biology screening (usually in preparation for DNA analysis) represents the next highest need for an increase in full-time analysts, followed by firearm and tool marks analysis and analysis of trace evidence, such as hair and fibers.

There is no industry wide agreement about what constitutes a backlog. Identifying a case-file as backlogged depends on time it stays in the laboratory without being reported. Some researches like the National Institute of Justice (NIJ), assume that case-files held for 30 days or more are classified as backlogged. Many FS laboratories, however, consider a case backlogged if the final report has not been provided to the agency that submitted the case. The definition one uses naturally affects the count of cases backlogged. In addition to the definition of a backlog, identifying the type of backlog is also important. In this study, case-file is assumed to be completed after a final report is signed by the Chief Government Chemist, and backlogs are counted for 7, 14 and 30 days (i.e., a week, 2 weeks and 4 weeks).

Establishing the exact numbers of backlogged case-files is complicated by the dynamic nature of the analytical laboratory business. This is because backlogs are not static. Backlogs are not a onetime event. They are dynamic and subject to the law of supply and demand. They may go up and down, when examined using time series plots. Forensic chemistry and Forensic biology and DNA laboratories backlogs, for instance, will exist until the supply (capacity of the nation's forensic science laboratories to test cases) surpasses demand (new service requests). Economically, this is a big challenge. In many forensic science laboratories, new analysis request submissions come in at a rate faster than case reports go out. A good example is the forensic chemistry laboratory where the largest number of case-files was being received daily in 2016. This means that the backlog of cases pending analysis will increase with time (determined as cumulative backlog). This does not mean that older cases will not be tested. Laboratories generally require more serious cases to be worked first, and the oldest cases in a backlog to be addressed before newer ones. 
Why is demand increasing for forensic testing in Tanzania, is a question that attracts attention of researchers. The demand for DNA testing, for instance, is rising primarily because of increased awareness of the potential for DNA evidence to help solve cases. The demand is coming from two primary sources: 1) the increased amount of DNA evidence that is collected in criminal cases; and 2) the expanded effort to collect DNA samples from convicted felons and arrested persons. For instance, the increase in demand for forensic chemistry analysis is mainly due to proper control of drugs of abuse, legality of owning firearms, and uncontrolled use of chemicals and precursor chemicals potential, for manufacturing drugs of abuse.

The forensic cases backlog within the FSL can have significant effects. Backlogs may delay legal proceedings that are waiting for results of analysis. On the other hand, backlogs can also prevent the timely capture of criminals, prolong the incarceration of innocent people who could be exonerated by evidence, and adversely affect families of missing persons waiting for positive identification of remains. Additionally, delays may increase the costs to contributors who must turn to private laboratories for testing because the public FSL is not able to produce timely results.

In Tanzania, public funds have been used to purchase automated testing equipment and high-throughput instruments, hire new personnel and validate more efficient standard operating procedures. Without this funding, the backlog picture would be much worse. The FSL management has several programs to help laboratories address their workload. Some programs address overall DNA backlog reduction; others are specifically for testing samples from convicted offenders and arrestees. Different strategies have been suggested to manage workload in FSL. Most laboratories engage special procedures to manage their workloads including the following strategies: prioritizing requests by investigative need, screening out requests for cases that will not be prosecuted, allowing customers to cancel requests for services no longer needed, assisting laboratories in the same system that have larger backlogs, and establishing backlog reduction programs with short and long term goals.

The program's short-term goal is to reduce the backlog of untested cases by providing crime laboratories with funds to work more cases. In-house long-term goal is to build the capacity of FSLs by providing funds to purchase high-throughput instruments capable of processing multiple samples at the same time, automated robotic systems and laboratory information management systems to manage the data generated more efficiently. Funds can also be used to validate newer, more efficient laboratory procedures and hire additional personnel. Out-sourcing is normally not practiced in Tanzania, especially for cases that require forensic science laboratory analysis.

The use of a laboratory information management system (LIMS) can enhance the ability of a laboratory to manage its caseload and to create a database with useful reporting capabilities [1] [2] [3] [4]. Literature shows that, im- 
plementation of LIMS can reduce backlogs, allow for effective tracking, and also assist personnel and laboratory management. This study established forms and datasheets to track turnaround times and backlogs. In the FSL, evidence can require testing in multiple case working laboratories, while some pieces of evidence from a case may not require any forensic testing. Testing evidence in multiple laboratories leads to extended turnaround time (TAT), hence case-files enters backlogged form. Evidence receiving personnel maintain a paper-based chain-of-custody to record inter-unit exchange of evidence. Determining backlog statistics and tracking cases through the FSL is intensive without automated systems.

The FSL in Tanzania is under a great pressure to keep up with increasing case-file workloads. Demand on the FSL in Tanzania has expanded leading to the proportion of the backlogged cases to increase accordingly. This problem led to the initiation of this study in order to quantify the backlogs and hence find means of reducing the backlogs. Due to FSL's backlogs and lengthy turnaround time, customer frustrations have been on rise caused by the need to complete the analysis in time for scheduled hearing dates and general court decisions. Most laboratories are undersized, underequipped, understaffed, and overwhelmed with backlogged evidence analysis requests. FSL has extremely limited capability in the type of toxins, drugs of abuse, and blood drug analysis that can be conducted, and as mentioned earlier, it has suffered with backlogged evidence analysis requests for many years. In this study, data on backlogs collected from three different FSL disciplines from three different FS in three consecutive years was analyzed. This study forms the backbone of the laboratory expansion efforts currently being undertaken by the FSL management.

The concept of forensic evidence analysis and bottlenecks leading to creation of stress Backlogs, can be explained using the increasing number of requests, connectedness with stakeholders with large number of cases to handle (police investigators, prosecutors and the judiciary). Figure 1 shows some of the activities conducted by the FSL leading to bottlenecks in the workflow. Case-file analysis is performed by receiving request for evidence analysis from the requesting authorities. Such forensic evidence is collected from crime scenes, victims and suspects in criminal cases and then submitted to the respective FSLs. Processing this evidence is time wasting as it must be screened first to determine if there is any biological material or chemical in question and if so, what kind of biological material or chemical group is present and from what origin of species or chemical category (illicit or controlled substances). This is followed by determining the amount of substance in question (chemical of DNA) only then can DNA testing begin. In addition, some samples can be degraded or fragmented or may contain DNA from multiple suspects and victims or chemical which are combined or masked. However, backlogs has become a problem in FSLs because demand for scientific test results (services) is increasing in Criminal justice system while the capacity of laboratories to process cases remains the same with its bottle neck. 


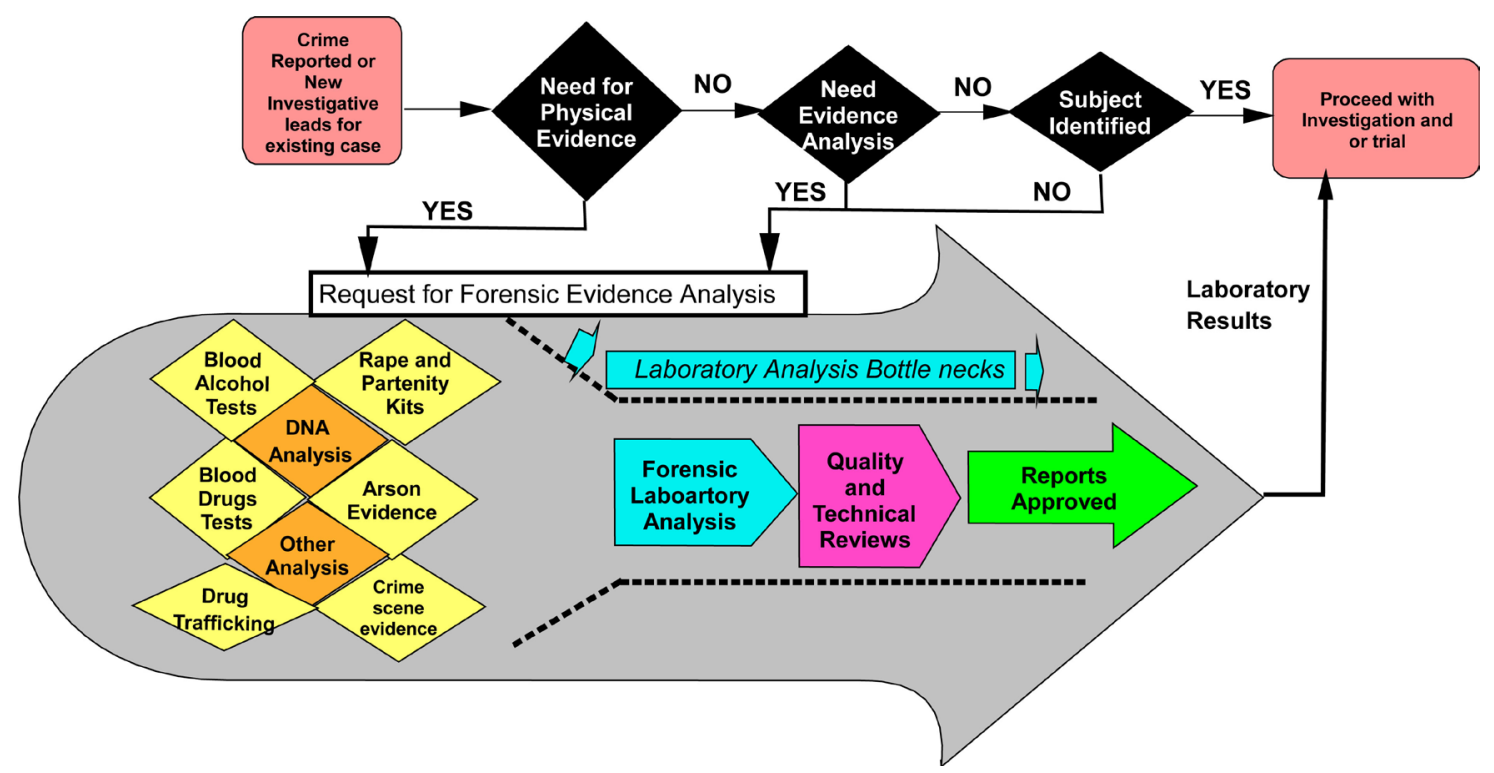

Figure 1. Forensic science laboratory evidence analysis workflow showing bottleneck due to increasing number and types of analysis requests with its connection to the major clients.

Based on Figure 1, the fact that technology for forensic laboratory analysis changes faster, there is a need of new supplies such as software's, equipment and timely delivered reagents and maintenance services. Quality and technical reviews is important to meet the international standards such as the ISO 17025 and 17020. In addition, skilled personnel who can interpret and approve the technical report are required all the time. A forensic technical report needs to be written clearly and effectively, as it engages the readers and their needs (investigator, prosecution or the judiciary), while also meeting the report's objectives. While approving, the report should be structured to have a maximum impact and the approver should edit with an eye for errors and improvements that can be made and hence present a report that appears professional. Therefore, according to Figure 2, such bottlenecks will cause a delay in deciding whether forensic results received can proceed with the investigation or trial or if there are new investigative leads obtained.

\section{Literature Review}

\subsection{Categories of Backlogs in Forensic Science Laboratories}

Laboratory backlogs are usually expressed using number of samples submitted to the FSL expressed on monthly [5] or yearly basis [6] [7] [8]. Others report also categories of cases whether requested but not yet analyzed or potential cases unrequested (Goulka et al., 2010). Some researchers report the nature of case-files backlogged as homicides and rape cases [8] [9], crimes against person [6] and property crimes [6] [8] [9]. Other researchers eliminate and report laboratory backlogs by stating the type of analysis required such as DNA analysis sample [1] [2] [3] [7] [10] [11] [12]. In California, for instance, the total backlogs were expressed for the core forensic disciplines such as alcohol, biology/DNA, fire arms and con- 
trolled substances [13].

The backlogged cases exist in both forensic science laboratories (such as, DNA laboratories reported above) and in the law enforcement agencies [9]. Forensic toxicology and chemistry backlogs are least reported in literature compared to DNA cases. Surveys on law enforcement evidence backlogs shows that property crimes are not routinely requested for analysis because, with limited capacity, more serious crimes have taken precedence with changing trend [7] [8] [9].

To reduce backlogs, the law enforcement officers have discretion on what evidence to send for analysis. In England, for example, police departments choose which sex-assault evidence should be subjected to DNA testing [14]. Anything not submitted to the FSL is not regarded as backlog in the law enforcement shelves. Backlogs in FSL have attracted attention of the public, pressure groups in the world [15], media [16] [17], leading to wider range of responses from elected officials, and law enforcement leaders [16] [17] [18] [19]. To eliminate backlogs in FSL, some laboratories have adopted information technologies designated to improve laboratory workflow LIMS [3]. Computerized systems like LIMS can receive and catalog requests, track evidence and sample, and report location and status during analysis, and facilitate the creation, dissemination and archiving of reports [1] [2].

\subsection{Backlogs of Forensic DNA Evidence}

The DNA evidence backlog is complex and requires an understanding of the types of backlogs that exist and the ways forensic science laboratories work. The average time that it takes the FSL to provide DNA testing results, for example, is lengthy especially in USA, where it takes turnaround time ranging from approximately 150 days to over 600 days [12]. Additional staffing with the expertise to perform DNA analysis would assist in reducing the backlog, while the management is pursuing various strategies to help reduce the forensic DNA case backlog.

This study has been able to identify the type of backlog being referenced (that is, DNA casework backlogs, toxicology and chemistry backlogs). In addition, some samples can be degraded or fragmented requesting extra time due to produced partial genetic profile with allele and/or locus dropout [20], which leads to extended TAT and hence backlogs. In this study, untested evidence collected from crime scenes and stored in law enforcement evidence rooms that has not been submitted to a FSL for analysis was not considered as FSL backlog. In this study, data has been captured by using dates of submission and report approval, by examining case by case throughout the year. Addressing the Forensic DNA Casework Backlog has been a continuous effort in FSL, such that the FSL has increased its capacity to work cases significantly, although the laboratories are unable to completely eliminate the backlogs.

\subsection{Backlogs in Forensic Chemistry Testing}

This laboratory is responsible for controlled substance/illicit drug analysis, ar- 
son, etc. Drug problems in our communities have escalated recently in Tanzania. Law enforcement is in a continual fight against illegal drug manufacturing, possession, sale, and use. Crimes committed due to drug use and abuse range from burglary, to robbery/armed robbery, rape cases and murder. Proprietors of this type of crime are usual in the middle of their criminal character and often have a history of drug abuse [21].

Currently, large quantities of drug evidence are collected and submitted to forensic science laboratory at GCLA. New designer drugs emerge regularly, requiring forensic science laboratories to develop new analytical techniques and spend more time on analysis. Both situations add to the substantial evidence analysis backlogs. In many cases, timely analysis of substances is of critical importance in numerous ongoing investigations. Although results are reported timely compared to DNA testing, forensic chemistry laboratory has a controlled substance analysis backlog of cases. Unfortunately, those backlogs are not due to lengthy analysis and confirmation of a particular drug, but rather, for a laboratory test reports for drugs. This is caused by large number of submission and sample influx [22]. When results require repeated work, case-files with masked samples or mixed products, etc., the forensic scientists require extended turnaround times to resolve the analytical challenges, leading to increased backlogs. The controlled substance/illicit drug backlog is partly due to the laboratory being least funded with less equipment, even when analysts are added to increase the analysis capacity.

It should be noted that, forensic chemistry laboratory does most of the Drug Urine Investigation (DUI) blood analysis (alcohol and other drugs) controlled substance analysis. The prescription opioid pain relievers and heroin kills many people due to overdose. Common drugs involved in prescription opioid deaths include: methadone, oxycodone, and hydrocodone. Large quantities of drug evidence are collected and submitted to FSL, with types ranging from heroin, cocaine hydrochloride, bhang (Cannabis sativa sp.), mirungi-khat (Catha edulis) and others. In many cases, timely analysis of substances is of critical importance in numerous ongoing investigations. Undercover detectives, drug task force officers, patrol officers, and others conduct drug buys, reverse buys, and related operations to identify and apprehend drug dealers, traffickers, illicit drug manufacturers, etc. Failure to correctly determine that a substance is in fact a particular drug; or that a substance is not the purported drug, but rather, a fake non-drug substance may poses significant problems to the investigations.

Supporting the criminal justice system with timely facts is a critical component of FSL competitiveness. There are raised concerns regarding the use of field-level presumptive tests for suspected drugs. Some FSL promotes and supports the use of presumptive tests for drugs in lieu of some of the traditional steps in the criminal justice system processes. In some forensic laboratories, pills and many types of capsules that are received for analysis merely undergo a physical examination of the size, shape, color and markings. Those features may be compared against 
reference sources such as a similar printed or electronic reference source. The FSL conducts confirmatory analysis using a Gas Chromatograph Mass Spectrometer (GCMS) for the purpose of reliability and accuracy [23] [24]. However, many illicit drugs are manufactured in a manner (disguised) to duplicate the physical size, shape, color, and markings of prescription medications, etc. The reference sources often used to examine such evidence in a criminal case are not accurate to any known degree of uncertainty.

\subsection{Backlogs in Forensic Toxicology}

The charter for forensic toxicology at GCLA states 14 days from receiving to issuing of the laboratory results, although this time is often exceeded, leading to backlogs. Other laboratory reports take even longer backlogs. The toxicology section for instance, has the unique capability to complete blood alcohol evidence analysis from DUIs in approximately 3 to 4 weeks, that is, 21 to 28 days. Such attended tests lead to longer TAT and backlogs. Low analysis capability reduces the ability to solve crimes, prevent crime, and save lives and keep the customers comfortable and satisfied. Without sufficient forensic toxicology laboratory capacity and capability, not all potential evidence can be recovered, some evidence becomes unusable, many cases are not prosecuted, and numerous cases remain unsolved.

The toxicology laboratory at GCLA is the only laboratory in the country, such that it must have sufficient capacity to offer full service of forensic evidence analysis. Forensic toxicology requires large evidence processing work space, specialized equipment, laboratory facilities (freezers and cold rooms, digesters, fume hoods, etc.) office, and support areas to conduct the analysis and other associated actions correctly and in a timely manner.

Compared to forensic chemistry, in addition to increasing in demand (requests) of the use of forensic science in judiciary system forensic toxicology faces a challenge of isolating metabolites in human body remains such as organs to trace toxic substances, leading to backlogs. The toxicology laboratory is overwhelmed with evidence backlogs of its own. The FSL does not have sufficient forensic laboratory capacity to process all of the available toxicological evidence from crime scenes. Much of the potential evidence sits on cold room shelves without undergoing processing and analysis (i.e., backlogged) due to poor sample collection techniques.

\section{Methodology}

\subsection{The Concept of Stress Backlog}

In this study, backlog is caused by various factors, including environmental factor; reduced efficiency no skills, less experienced staff; it may also be due to reduced abundance of resource constraints, such as human resource, lack of facilities (poor infrastructure), or inconsistency of supply chain. In addition, inconclusive cases or weak technical strategies may lead to backlogs and extended 
TAT. These factors have attributed to different workloads which not limited to unattended case-files, pending samples to be analyzed, increased Turnaround time for analysis, unsatisfied clients/customers external and within the organization. Dealing with such unexpected responsibilities and pressure that do not align with normal FSL activities, knowledge, skills or expectations of the analysts has been defined in this study as stress backlog. Thus, stress backlogs were determined as number of case-files unattended that cause stress among FSL employees.

A backlog may be of either administrative type (forms that need filing, documentation, instructions, and analytical reports to be written or reviewed), that keeps piling up on FSL manger's desk, for instance. This causes an extended total TAT and slowly the FSL performance starts decreasing. Stress backlog drains the energy and reduces the competitiveness of FSL which then takes its focus away from where it should be. Backlog may have an impact on the FSL's future earnings, as it is unable to meet demand. Thus, stress backlog is a buildup, undone or pending work that needs to be attended and completed. In this study backlogs of case-files within the FSL were determined and evaluated.

\subsection{Determination the Stress Backlog}

The number of backlogged case-files was determined on each work station by comparing case-files in and case-files out, in a specified time interval, say 7 days, as shown in Figure 2. The backlogs were determined for SRO work station, for example, by the Equation (1):

$$
A-B=\alpha
$$

For SRO as a work station, backlogs are created while receiving and distributing case-files, such that $A$ is the number of case-file received at SRO's office, $B$ is the number of processed case-files (transferred to CGC for instructions submitted) and the difference between A and B is the stress backlog, denoted as $\alpha$.

The flow streams from A (request) to $\mathrm{K}$ (reports), contain different actions including instructions (A to E), sample submission by SRO (E), analysis, report preparation (E to F), report review $(\mathrm{G}, \mathrm{H})$, report approval $(\mathrm{H}, \mathrm{J})$ and report collection $(\mathrm{K})$. All these actions points suffer from piling uncompleted tasks, when

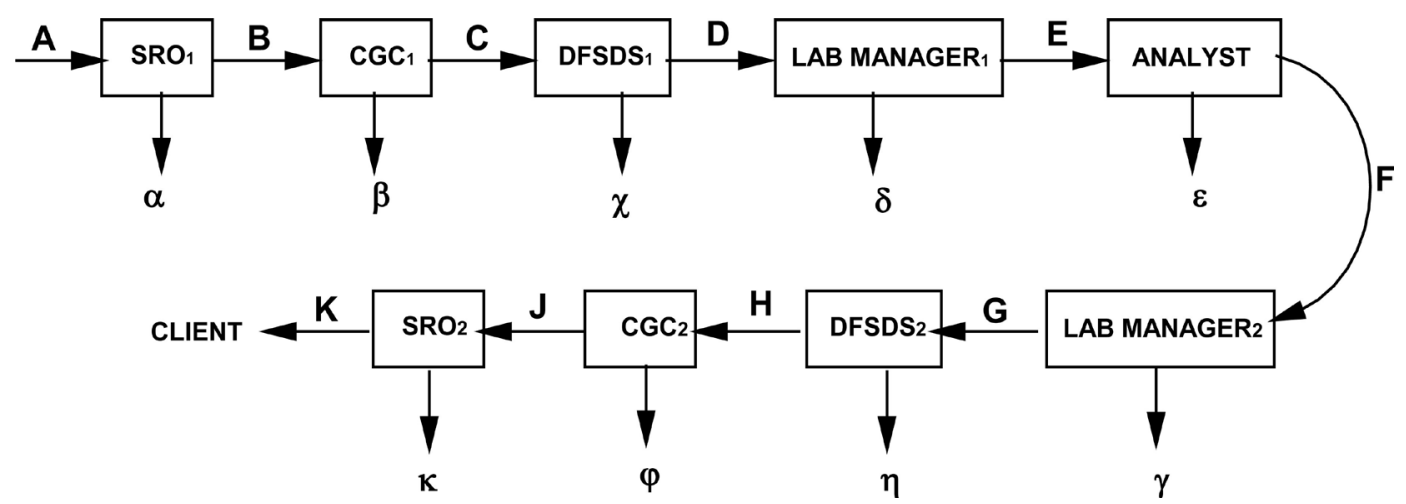

Figure 2. Flow of chart for case-files and stress backlog model. 
assessed in 7, 14 or 30 days periods, defined in this study as stress backlogs. At each point, a comparison of case-files received and completed, leads to number of case-files backlogged. Analysis of all kinds of backlog from $\alpha$ to $K$ in Figure 2 is a complex engineering problem which requires a separate study.

It should be noted that for SRO's office, another type of backlog is defined using symbols " $K$ ", that is, the analytical reports remaining there without being delivered to the clients or uncollected reports. Also, only the analysts has one type of backlog that is, which appears once (once through) denoted as " $\mathcal{E}$ " in Figure 3, with subscript " $c$ " denoting case-files. All other blocks have two types of backlog for case-file receiving process to the analyst level, and report flow from analyst to the client (i.e., each case-file passes these points twice). For simplicity of analysis in this study, the case-files backlog is thus defined for combined blocks $\mathrm{SRO}_{1}$ to $\mathrm{CGC}_{2}$, leading to general or overall $B_{g c}$ defined as per Equation (2):

$$
B_{g c}=\left(A_{c}-J_{c}\right)
$$

Defining $N_{c r}$ and $N_{c p}$ as number of case files received and processed, respectively, across the FSL, leads to the overall backlog Equation (3):

$$
B_{g c}=\left(N_{c r}-N_{c p}\right)
$$

Equations ((2) and (3)) apply for overall backlog analysis regardless of the FSL discipline. When backlog data for specific discipline is required, a section is made across point $\mathrm{D}$ and the former point $\mathrm{J}$ in Figure 2, leading to Equation (4) for each laboratory discipline:

$$
B_{g c, i}=\left(D_{c, i}-J_{c, i}\right)=\left(N_{c r, i}-N_{c p, i}\right)
$$

where $i=1,2,3$, representing the three laboratory disciplines.

Specifically, the quantity $B_{g c}$ comprise of all delayed processes from $\alpha$ to $\varphi$ as per Equation (3). Although several backlogs are defined as per Figure 2, in this study however, only $B_{g c}$ was assessed. While there are backlogs of case-files in all steps of case-file processing ladder, the backlogs are different in nature covering samples, un-submitted samples, and untested, unveiled instructions, incomplete reports, unreported reports, un-dispatched reports, etc. Analysis of such backlogs is complex. This study focuses on backlogged case-files after submission to the laboratory manager, director up to final approval by CGC, as per Equation (2). It should be noted that the backlog represented as $K_{c}$ was removed in the analysis because it depends on external client's performance in collecting the reports, and is beyond FSL's control. Moreover, the above analysis covers only backlogs in case-files, which travel from point $\mathrm{A}$ to $\mathrm{K}$ in Figure 2 different from samples, which start at point $\mathrm{A}$ and ends at point $\mathrm{F}$, after analysis is completed.

\subsection{Time Interval for Backlog Determination and Statistical Analysis}

Depending on the nature of backlog, the time interval for defining backlog will differ. For example during case-file processing or sample processing, 7, 14 or 30 
days interval can be used. Backlog involving administrative or approval processes require estimation starting from 2 days to 30 days. The data for backlog using $B_{g c}$ was established on weekly basis, as baseline time interval. Based on the analysis conducted in this study, that is, case-files only, backlogs were initially recorded based on weekly basis (Table 1 ) which can be transformed into 14 days (bi-weekly backlogs) and 30 days (monthly backlogs). As shown in Table 1, the final results at the end of a calendar year are the same. The bi-weekly backlog data is useful when results are to be compared with the laboratory service charter for FSL. In this study 7 days, or one week (five working days) was used as a reference time, so that $N=52$ weeks, is long enough for statistical analysis. Statistical analysis was conducted by estimating average values, standard deviation, skewness and kurtosis of 7-day (weekly) backlogs, with $N=52$ (weeks per year).

\subsection{Negative and Positive Backlog Values}

Given a total number of case-files received into the FSL discipline per week (Figure 3 ), if the number of case-files received is higher than the number of case-files reported or processed (case-files out) then, $B_{g c}>0$ and the backlog value is a positive integer. This implies that the specific laboratory is creating new backlog. On the other hand, when $B_{g c}<0$, it means many case-files were reported than received, indicating that the respective discipline of FSL was dealing (processing) withheld or formally backlogged cases as a means of dealing with backlogs elimination.

\subsection{Determination of Percentage Case-Files Backlogged}

Let $N_{c r}=$ number of case-files received into the FSL and that, at the end of the year $N_{c p}$ case-files are processed and reported, then the percentage case-files

Table 1. Determination of weekly backlog during case-file processing in forensic biology/ DNA for 2016.

\begin{tabular}{|c|c|c|c|c|c|}
\hline $\begin{array}{l}\text { Week } \\
\text { No. }\end{array}$ & $\begin{array}{l}\text { Starting } \\
\text { Date }\end{array}$ & Ending Date & $\begin{array}{l}\text { Case-Files } \\
\text { Received, } N_{c r}\end{array}$ & $\begin{array}{l}\text { Case-Files } \\
\text { Reported, } N_{c p}\end{array}$ & $\begin{array}{l}\text { ly Backlog, } \\
B_{g c}\end{array}$ \\
\hline 1 & 04-Jan-16 & 08-Jan-16 & 5 & 7 & -2 \\
\hline 2 & 11-Jan-16 & 15-Jan-16 & 4 & 13 & -9 \\
\hline 3 & 18-Jan-16 & 22-Jan-16 & 4 & 23 & -19 \\
\hline 4 & 25-Jan-16 & 29-Jan-16 & 15 & 33 & -18 \\
\hline$\cdots$ & $\cdots$ & $\cdots$ & $\cdots$ & $\cdots$ & $\cdots$ \\
\hline 50 & 12-Dec-16 & 16-Dec-16 & 20 & 0 & 20 \\
\hline 51 & 19-Dec-16 & 23-Dec-16 & 20 & 1 & 19 \\
\hline 52 & 26-Dec-16 & 30-Dec-16 & 0 & & 0 \\
\hline \multicolumn{3}{|c|}{ Total case-files received } & 395 & Percent case-files reported & $89.9 \%$ \\
\hline \multicolumn{3}{|c|}{ Total case-files reported } & 355 & Percent case-files backlogged & $10.1 \%$ \\
\hline
\end{tabular}


backlogged, $P_{c g}$, can be determined from Equation (5):

$$
P_{c g}=\left(\frac{N_{c r}-N_{c p}}{N_{c r}}\right) \times 100 \%=\left(1-\frac{N_{c p}}{N_{c r}}\right) \times 100 \%
$$

Equation (3) can be used regardless of the time interval used to define backlogs $(7,14$ or 30 days, or 1 year).

\section{Results and Discussion}

\subsection{Overall Analysis of Case-Files Received and Reported by FSL}

In the FSL, there are three laboratories which mainly receive forensic case-files (forensic toxicology, forensic chemistry and forensic biology/DNA). However, three other laboratories receive case-files for analysis of product quality, microbiology food, drugs and environmental management, but also support the FSL where necessary. In all six laboratories, there is a big difference in the number of case files received $\left(N_{c r}\right)$ and processed and reported $\left(N_{c p}\right)$, a comparison of which is shown in Figure 3 (for Y2016). Forensic chemistry laboratory receives and processes the largest number of case files followed by forensic biology/DNA, as summarized in the pie chart for $N_{c r}$ data. To express the extent of case files backlogs, a comparison between $N_{c r}$ and $N_{c p}$ values for the five laboratories is presented in Figure 3.

Figure 3 shows also that, in forensic chemistry laboratory $N_{c r}$ is almost equal to $N_{c p}$ in most laboratories (with exception of forensic toxicology) that is, the FSL has reached a point where the output or analytical reports released is equal

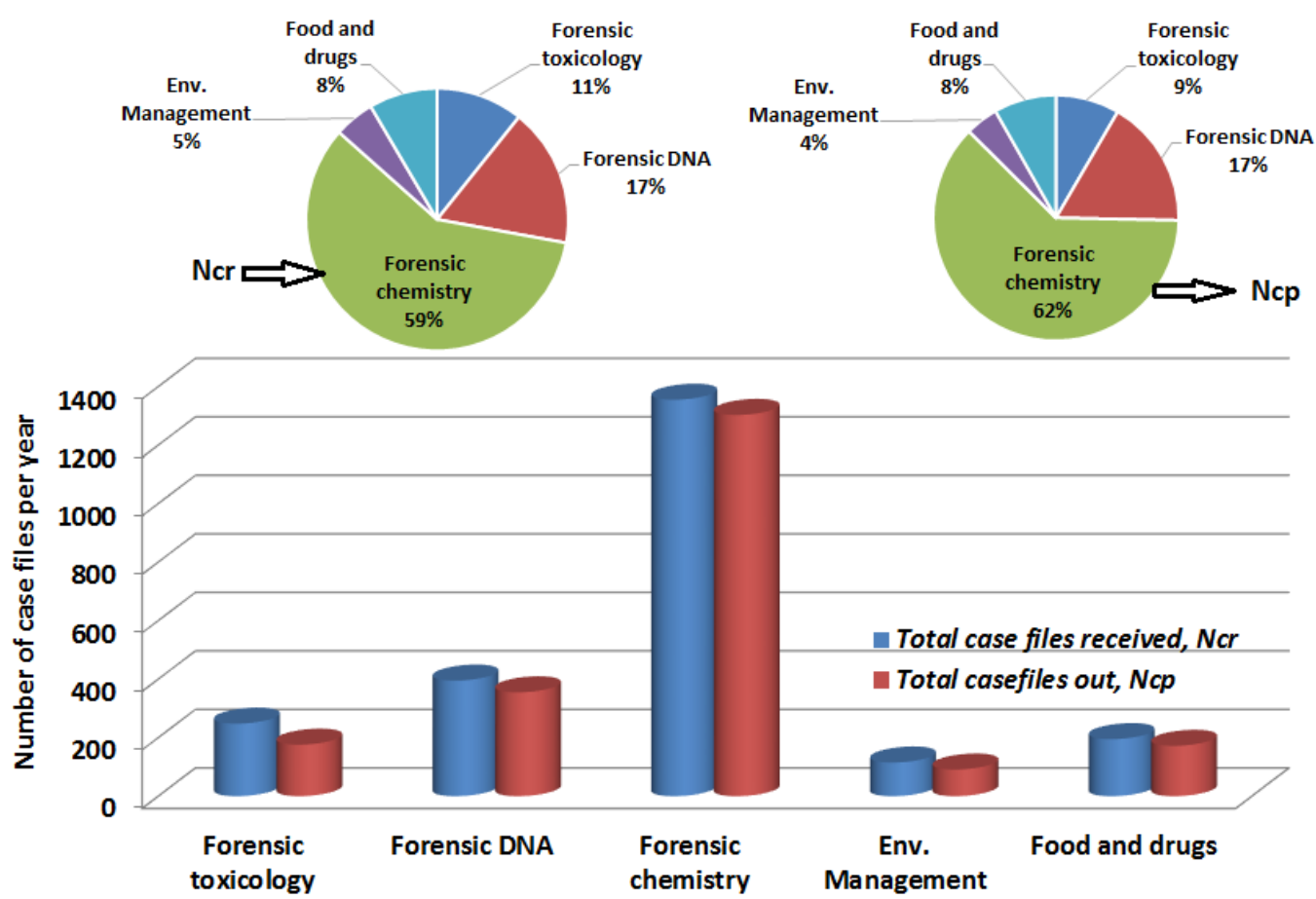

Figure 3. The number of case-files received and reported per year and its distribution in different GCLA laboratories (for Y2016). 
to demand based on the requests received from different authorities. This shows that the performance of FSL has increased in terms of case-file processing, attending case-files submitted for analysis requested for forensic chemistry. The higher values of $N_{c r}$ and $N_{c p}$ indicate that there is increase in demand of forensic chemistry services compared to other FSL services. This may be due to increase in quality of analytical reports and reliability of results. This can be attributed to the fact the FSL has increased spending in advertising and training of stakeholders especially during public events.

Large number of case-files $\left(N_{c r}\right)$ in forensic chemistry causes staff to consume most of their working hours dealing with backlog elimination since such surge in case-files in one laboratory discipline causes backlogs in other laboratories as more manpower is directed towards that laboratory. Analysts from other disciplines are always re-allocated to help reduce the piling case-files, especially during instrumental analysis and drafting the reports. This means there is re-allocation of staff and budget from other disciplines of FSL, because reagents and chemicals are consumed more than what was planned. Therefore, an increase in budget or re-allocation of funds is inevitable. To minimize backlogs, emergency fund for electricity and water bills (as utility) is consumed faster than the normal rate. Differences in percentage distribution of $N_{c r}$ and $N_{c p}$ among different laboratories, are a clear picture of differences in demand placed on the laboratories and performance (how much is managed by each laboratory).

Forensic laboratory analysis to support investigations is costly but the parties commissioning these investigations are often unaware of this fact. For them, the forensic laboratory investigations are "free", and they behave as if there are no financial or capacity limitations. This is a major problem that has created backlogs in FSLs. Backlog elimination causes other work in the FSLs to drag behind due to inconveniences caused by extra expenditure sharing and shifting analysts, increased need for new staff allocation, frequent review of the budget and strategic plans which impact the FSL competitiveness negatively.

\subsection{Analysis of Case-Files Influx into Different FSL Disciplines}

The statistical analysis of the case-file influx into the FSL in three consecutive years is presented in Table 2. While the mean case-file influx shows the number of case-files per week, standard deviation gives an estimate of the fluctuations in the data for $N=52$ weeks. The values of skewness shows that the inherent probability

Table 2. Statistical analysis of the weekly case-file influx into forensic science laboratory in the three consecutive years (Y2014 to Y2016).

\begin{tabular}{|c|c|c|c|c|c|c|c|c|c|}
\hline & DNA-Y2014 & DNA-Y2015 & DNA-Y2016 & TOX-Y2014 & TOX-Y2015 & TOX-Y2016 & CHEM-Y2014 & CHEM-Y2015 & CHEM-Y2016 \\
\hline Mean, $N_{c r}$ & 6.19 & 3.04 & 7.75 & 2.12 & 0.92 & 3.12 & 6.67 & 5.46 & 26.06 \\
\hline Skewness & 0.78 & 0.67 & 1.84 & 1.16 & 1.58 & 1.30 & 1.06 & 1.12 & 0.70 \\
\hline Maximum & 15.0 & 10.0 & 27.0 & 8.0 & 5.0 & 12.0 & 21.0 & 19.0 & 86.0 \\
\hline
\end{tabular}


distributions of the case-file influx data are closer to the normal distribution, but slightly skewed to the right hand side (towards higher values of case-file influx per week). The maximum values indicate the largest recorded number of case-files received per week in the respective laboratories for each calendar year.

It should be noted that the case-files received during each week are regarded as new cases, while case-files processed and reported during a given week may include those accumulated in the former weeks. The unattended case-files at the end of the week are regarded as backlogs regardless of when they are received. Similarly, on annual basis, unattended case-files at the yearend are included as backlogs in the following calendar year. Figure 4 presents the weekly average data for new case files received or a demand for forensic analytical services for the three consecutive years.

The capacity of laboratories to complete cases-files grew at about the same rate as new cases were submitted, as shown by the "completed cases" data. But the number of new cases submitted grew faster than did the capacity to process the new and present workload, hence, a backlog. Backlog is partly the result of repeated decisions by the law enforcers by submitting new or extra samples in particular cases that had been already completed the laboratory analysis. Most of the forensic laboratories refuse to straight identification which involves a drugs analysis case work without a suspect. Thus, such cases may be pending to the submission of the suspect's reference sample adding to backlog. This is observed in more serious cases such as those of rape, murder which need biology/DNA testing. In any case, the growing reliance on forensic evidence to solve and prosecute crimes contributes to the increase in forensic case processing and hence the backlog.

Figure 4 shows the weekly case-file influx into the three FSL disciplines (forensic chemistry, biology/DNA and toxicology) for three consecutive years 2014, 2015 and 2016. In all the three years studied, the case-file influx was the highest

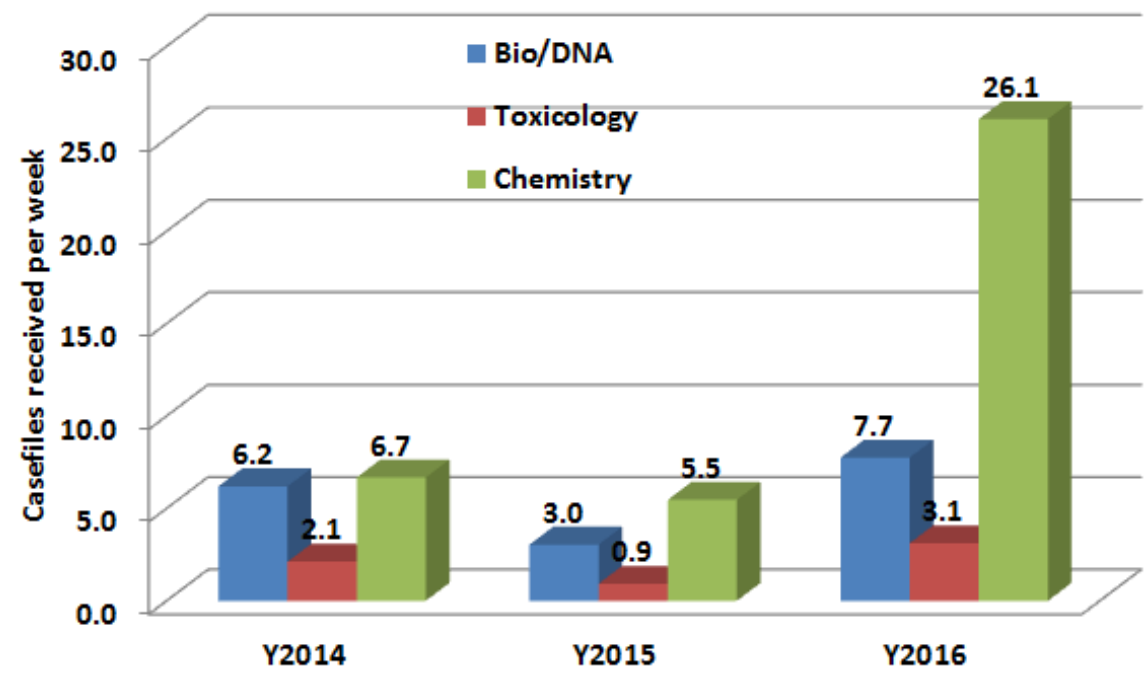

Figure 4. Average number of case-files received per week for three consecutive years (2014 to 2016). 
for forensic chemistry, which increased about four times in the Y2016. This increase led to higher demand for new, powerful and validated forensic detection methods which have the great effect in the criminal investigations. The $N_{c r}$ for forensic biology/DNA changed slightly to 6.2 in Y2014 to 7.7 case-files per week on average in Y2016. On the other hand, case-files influx for toxicology was the lowest (at a maximum of 3 case-files per week in Y2016).

However, the fact that forensic chemistry had more case-files received than any other forensic science discipline, calls for action on the two factors that have a significant impact on the caseload in forensic chemistry laboratory that is the crime rate and the scientific and technological capabilities of the laboratory. The way in which crime rate impacted forensic chemistry laboratory performance and the rest of the FSL is similar to the way it influences the broader law enforcement community. However, the impact of scientific progress and technological innovation is far more complicated, and clearly sets forensic chemistry laboratory apart from their main customers. Advances in forensic science technology tend to increase the caseload in the forensic chemistry laboratory sometimes dramatically even when the crime rate is not equivalently high. On the other hand, to various extents powerful forensic techniques replace more traditional and time-consuming investigative methods, or at a minimum can provide more focus to a criminal investigation.

Figure 5 shows the PDFs of $N_{c r}$ data from three FSL laboratories fromY2014 to Y2016. The PDFs of $N_{c r}$ data differ in shapes between different laboratories, showing that the case-file reception data differ and is also affected by different

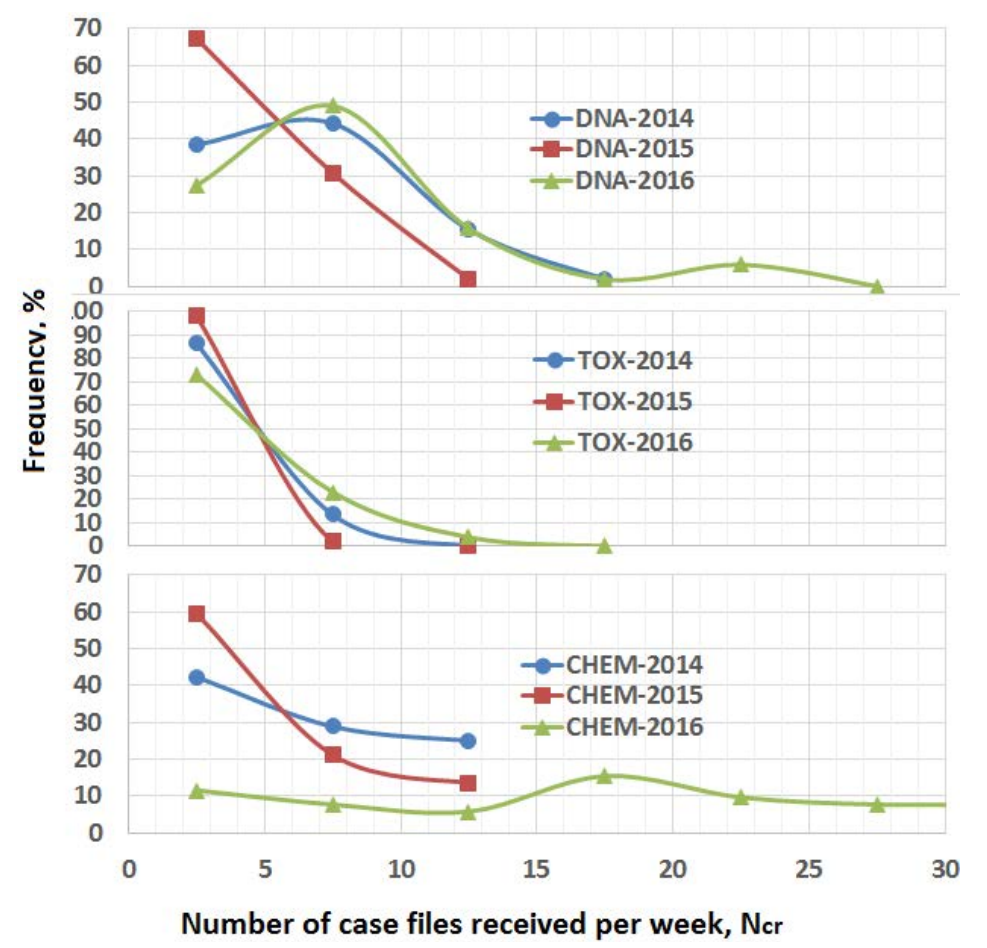

Figure 5. Probability density functions of the number of case files received per week for each FSL discipline for the three consecutive years. 
factors. This is due to differences in the nature and frequency of occurrence of crimes, skills among investigators that utilize the FSL disciplines. For instance, frequency of occurrence of poisoning incidences requiring toxicological analysis is different from crimes requiring DNA test. On the other hand, forensic chemistry case files involve crimes related to drugs of abuse, arson samples, explosives, etc., occurrence and frequency of which are completely different from toxicology cases. Comparison of PDFs will allow the FSL to plan for analytical capacity in the three laboratories in terms of utilities, financial and human resources. In Y2016, the PDFs can be characterized by wider span and long tails, showing that case-files are received in large numbers per week.

\subsection{Analysis of Case-Files Reported by Different FSL Disciplines}

Although drug evidence accounts for the largest share of forensic workload (compared to toxicology, biology/DNA analysis, and other requests), the process of identifying a controlled substance is not as time-consuming as other forensic functions. It was observed in this study that, forensic chemistry had processed about 25.1 case-files per week, being 6 times increase compared to Y2014, attributable to increased demand for analysis, as shown in Figure 6. In addition, highest case-files reporting in forensic toxicology was observed only in Y2016 at 3.4 case-files per week.

On the other hand, highest case-file reporting in forensic toxicology and biology/DNA was observed also in Y2016 at 3.4 and 7.0 case-files per week, respectively, as shown in Figure 6. This increased reported case-file per week for biology/DNA was contributed by increased capacity via purchase of new equipment which further streamlined the testing processes such as polymerase chain reactors (PCR), micro-centrifuges, vortexes, pipettes and a bone grinder for challenged samples. For toxicology laboratory, the increased performance in Y2016 can be attributed to the completion of rehabilitation of the laboratory in Y2015

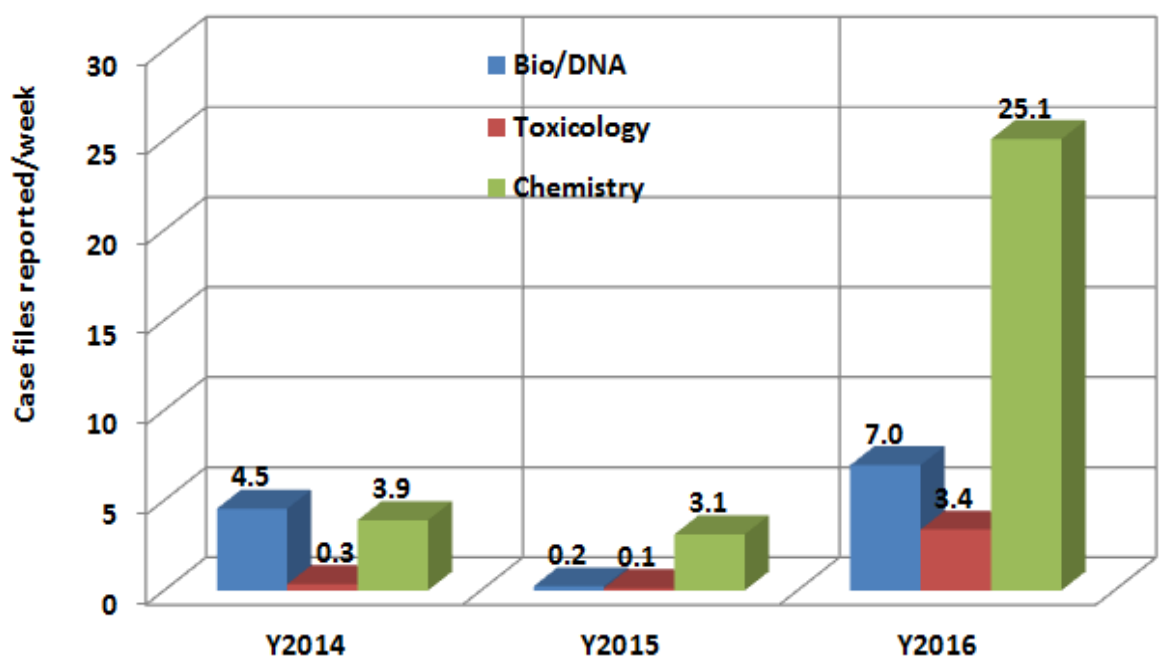

Figure 6. Comparison of case-files reported per week from different FSL laboratories from 2014 to 2016. 
and procurement of glassware, sample preparation facilities and placement of new support staff including laboratory attendants.

\subsection{Analysts' Workload Based on Case-Files Received and Reported}

Information on workload and performance of analysts (the average number of requests the analysts completes in a given period) can be used to determine which forensic disciplines is the overloaded or understaffed. Figure 7 shows the average case-file influx per analyst per year for the three consecutive years. The number of analysts available to carry out case-file processing is a key factor in dealing with backlog elimination even when enough facilities and resources exist. For biology/DNA, the number changed from 46 to 79 per analyst per year, from Y2014 to Y2016, respectively. The number of case-files received per analyst per year was the highest for forensic chemistry, which changed from 34.7 to 196.6 case-files per analyst per year between Y2014 and Y2016. This is a bottleneck for an acceptable analyst performance, since increased work load lead ultimately to customer complains because analysts' performance drops.

Figure 7 shows the number of case-files reported per analyst per year for three consecutive years and also for all three forensic science disciplines. The impact of fewer forensic scientists is clear from Figure 7, whereby, case-files reported per analyst per year increased from 33.7 (Y2014) to 71.0 (Y2016) for forensic biology/DNA, 1.8 (Y2014) to 25.1 (Y2016) for forensic toxicology and 20.3 (Y2014) to 186.1 (Y2016) for forensic chemistry while the number of analysts remained constant. While there is always a requirement to match capacity with demand for analysis, increased demand based on case files received, $N_{c n}$ and stagnating skills development contributed to observed increase in reports per analyst per year. While the number of case-files reported per analyst per year for forensic toxicology increased 14 times between Y2014 and Y2016, the workload was, however, overwhelming for forensic chemistry, during which the number of case-files reported

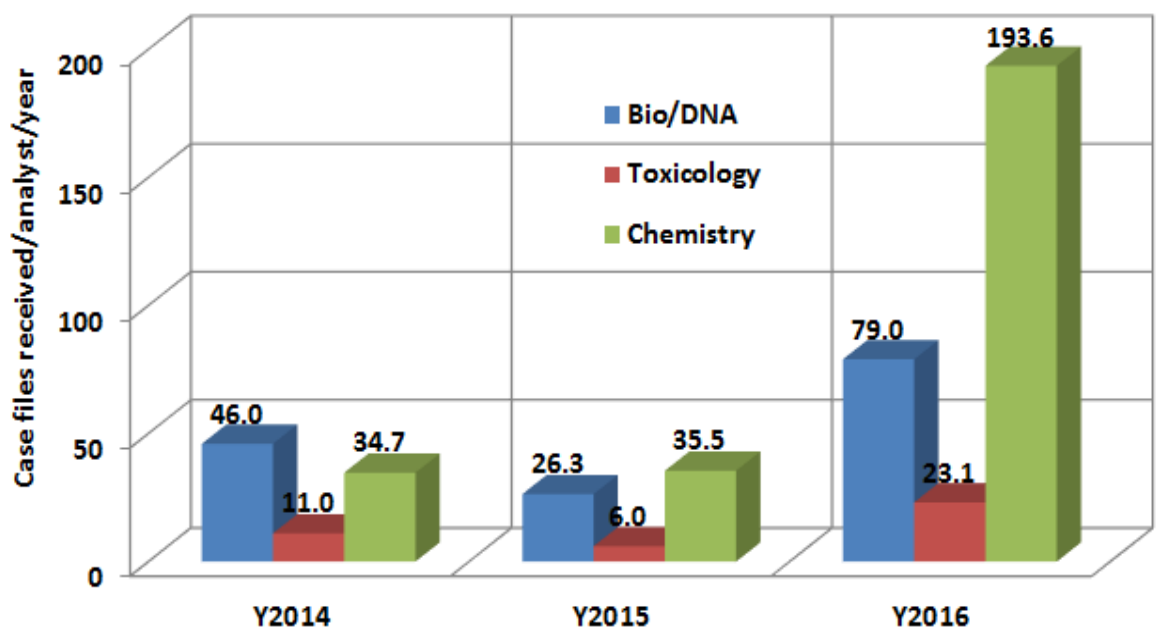

Figure 7. Analysis of case-file reported per analyst per year for three forensic science laboratories in three consecutive years. 
by each analyst rose about 9 times per year. It was further observed that, the actual case-file processing in forensic biology/DNA was approximately 33.7 (Y2014), 2.0 (Y2015) and 71.0 (Y2016) case-files reported per analyst year, about 2 times increase, as shown in Figure 7. This shows that the case-file processing capacity for forensic biology/DNA increased more than twice in Y2016 as compared to Y2014, while the highest increase was observed in forensic toxicology. Thus, the rehabilitation of forensic toxicology laboratory had stronger impact to the FSL competitiveness than purchase of equipment for forensic biology/DNA. The decrease in reporting capacity for the forensic biology/DNA laboratory in Y2015 can be attributed to internal challenges such as extended delay in repair of the DNA analyzer. Moreover, re-Allocation of analysts from other laboratories to the forensic chemistry improved the case-file processing capacity for FSL to match the demand.

Figure 8 shows the PDFs of $N_{c p}$ data (number of case files processed and reported) per week in the three laboratory disciplines from Y2014 to Y2016. Different from the $N_{c r}$ data, the PDFs for $N_{c p}$ have similar shapes, indicating that the factors affecting the FSL capacity in processing the case-files are similar for the three laboratories. The only difference is the span of $N_{c p}$ values, being highest for forensic chemistry followed by forensic biology/DNA and lowest for forensic toxicology. The shape of the PDFs for $N_{c p}$ data did not change between Y2014

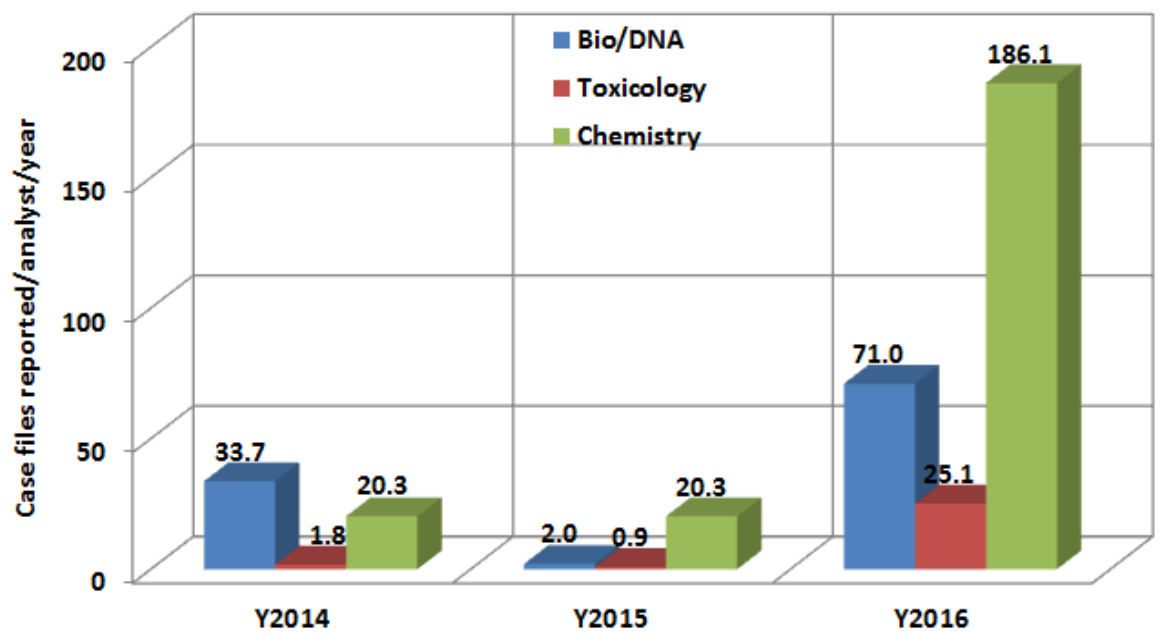

Figure 8. Case-files reported per analyst per year in different FSL laboratories from 2014 to 2016 .

Table 3. Statistical analysis of the case-file processed and reported by forensic science laboratory in the three consecutive years (Y2014 to Y2016).

\begin{tabular}{cccccccccc}
\hline Laboratory discipline & DNA-Y2014 & DNA-Y2015 & DNA-Y2016 & TOX-Y2014 & TOX-Y2015 & TOX-Y2016 & CHEM-Y2014 & CHEM-Y2015 & CHEM-Y2016 \\
\hline Mean, $N_{c r}$ & 4.54 & 0.23 & 6.96 & 0.35 & 0.13 & 3.38 & 3.90 & 3.12 & 25.06 \\
Std. Deviation, $\sigma$ & 5.96 & 0.73 & 8.97 & 0.97 & 0.40 & 4.36 & 5.84 & 5.44 & 22.70 \\
Skewness & 1.85 & 4.00 & 1.95 & 3.56 & 3.12 & 1.71 & 1.83 & 3.35 & 0.52 \\
Maximum & 25 & 4 & 42 & 5 & 2 & 16 & 24 & 32 & 82 \\
\hline
\end{tabular}


and Y2016, indicating that a common working culture exist in all laboratories which has not changed with time.

The key question answered by the results shown in Figure 5 and Figure 8 is whether the dynamics of case-file reception is the same as that of processing and reporting. The results show clearly that the two dynamical systems are different (different shapes of PDFs), leading to another complex dynamics of backlogs creation. Until when the two dynamics are forced to have the same characteristics, backlogs will remain a continuous and complex problem in FSLs.

Figure 9 and Table 3 provide the fitted probability distribution functions using EasyFit software to compare between $N_{c r}$ and $N_{c p}$ data or their inherent dynamics. The two data sets for Y2016 were described by three highly ranked distribution functions, both of which agreed Wakeby distribution function as the first ranking. Although the two data sets were described by Wakeby distribution function, the PDFs are completely different based on the parameters, as shown in Figure 9.

\subsection{Detailed Analysis of Backlogs Data in FSL}

Based on Table 1, Figure 4 and Equations ((2) and (3)), the difference between $N_{c r}$ and $N_{c p}$ expressed as a percentage of $N_{c r}$ gives the percent of case file backlogged, $P_{c g}$. Figure 10 shows the percentage backlogged case-files for different laboratories in GCLA for the year 2016. The percent of annual backlogged case-files
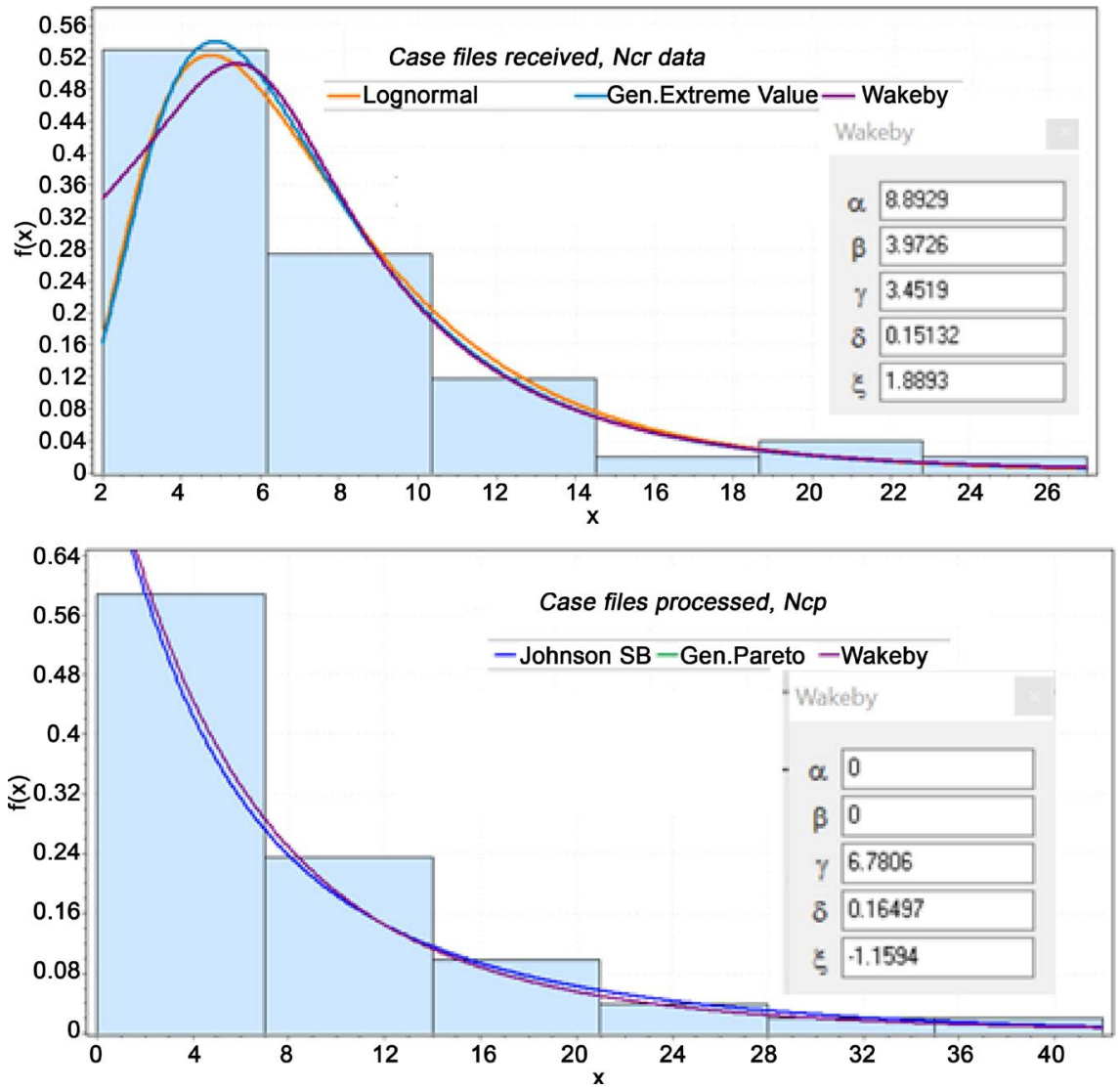

Figure 9. Fitting the probability distribution functions to the $N_{c r}$ and $N_{c p}$ data from forensic chemistry laboratory for Y2016. 


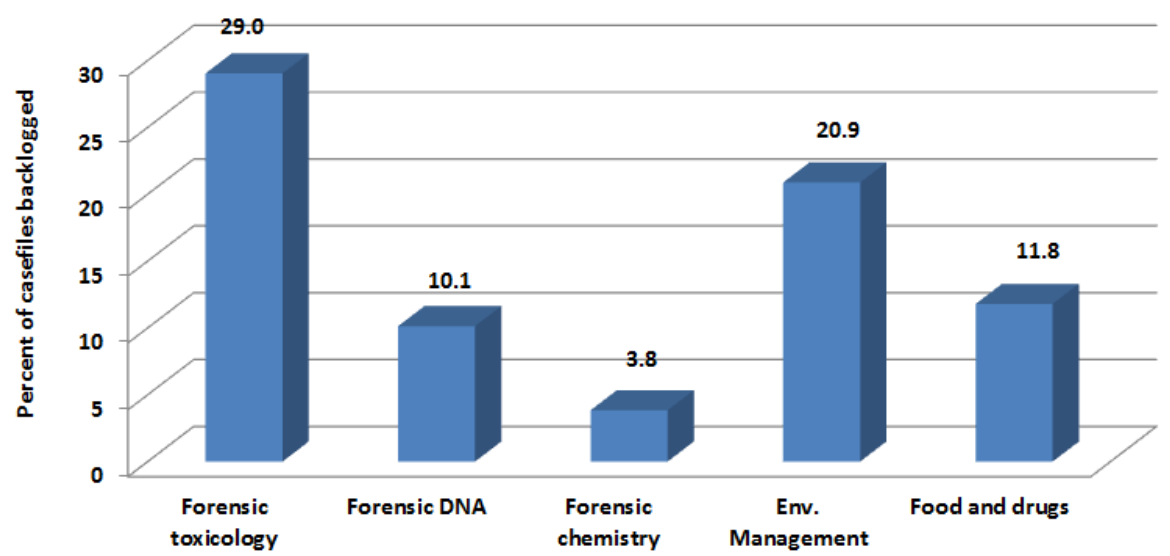

Figure 10. Percentage backlogged case-files for different laboratories in GCLA for Y2016.

for forensic toxicology is alarming, indicating that $29 \%$ of case-files were being backlogged. This can be attributed to lack of sophisticated equipment to analyze the toxicology samples thoroughly or efficiently. Moreover, a $10.1 \%$ annual back$\log$ rate for forensic biology/DNA is also worth noting.

The backlog rate for food and drugs laboratory and environmental management laboratory were presented in Figure 10 for comparison purposes, although the data presents an alarm to the FSL management. Case-files backlogs shown in Figure 10 have a large effect on customer satisfaction. Delay in release of results that is more than the 14 days stated in the client's charter, results in customer complaints. The value of $P_{c g}$ could also result from late submissions of requests in December 2016, which still necessitates administrative efforts by the FSL management. The increase in $P_{c g}$ causes the stakeholders (the judiciary, investigators and the pathologists) to have a drawback in managing their cases, especially where cases depend on FSL results in making their final decisions. Despite the large number of case-files received in forensic chemistry, it is interesting to note that the $P_{c g}$ at the end of the year is lower compared to forensic toxicology and biology/DNA.

In addition, the technology driven case-file reports, such as DNA, have more demand because forensic science services increases quickly for such type of evidence, but are often not adequately factored into the budgetary models used to allocate resources to different entities within the forensic science laboratory. The expected result of abrupt peak for demand on services is a backlog creation. An increase in demand caused by an innovative forensic procedure, does not spontaneously lead to a corresponding increase in financing as it does not come with creation of additional financial resources for publically owned entities. Also, most FSLs do not have service level agreements (SLA) with their customers or clients, limiting the amount of work that can be commissioned.

It should be noted that when the Government policies are in action, the sample influx increases abruptly, which creates surge on the laboratory workload and resource utilization. Currently, the criminal justice systems appreciate and willingly rely more on scientific results on decision making worldwide. This is observed as there is an increase in the number of case-files received and reported as shown in 
Figures 4-6 in relation to the number of backlogged case-files shown in Figure 10. This means that, there is legal pressure from the clients as compared to other laboratories of different field in forensic science or non-forensic disciplines of the laboratory (such as environmental management, foods and drugs laboratories). As stated above, however, when the FSL uses a new technology that allows releasing more elaborative and precise laboratory results using a technology that reduces time of report production hence reducing the turnaround time, the budgeting system does not automatically support the move. This means that backlogged case-files within the FSL is only reduced by fast pace of equipment as shown in Figure 10. However, there may be a large number of case-files that are pending within the law enforcement departments which need laboratory testing, caused by poor communication between the laboratories and law enforcement departments, and which is not counted as FSL backlogs in this paper.

Case-files backlogged for forensic toxicology was very high in Y2014. The working environment for forensic toxicology laboratory was very complicated and it has never been managed up to the time of this study. It required intensive renovation in terms of working environment, space and specialized equipment and instruments, such as external cold rooms, macerators, and sensitive instruments such LC-MS-MS for toxins characterization and poison detections. In addition, more specialized or experienced staff are required, for instance, staff with medico-legal experience and practices. Currently, they are only staff with general chemistry and molecular biology backgrounds.

The intense amount of resources and staffing necessary to complete the casework may be the cause of high percentage of backlogged case-files in forensic science laboratories such as the forensic toxicology and environmental management laboratory (as shown in Figure 10). Also, the salaries for laboratory analysts and technicians in FSL are not competitive with private industry with the former working in difficult environment. That is, public laboratories mostly serve as training grounds for analysts before they move to green pastures and better positions in the private laboratories or other high-paying institutions.

The case-files received and processed in the FSL differ in respect of the type of cases handled and the type of samples received within the same case-file even if they belong to the same discipline. The disparity among samples and case-files depends on crime scenes where the samples are collected, the mode of collection and the type of samples within that specific case. Case-files with biological or ani$\mathrm{mal} /$ human remains tend to have complications during laboratory analysis as they require intensive processes in sample preparations before the exact chemical or biological, ingredients or component or the unknown product is identified.

In other forensic disciplines such as forensic chemistry, there are few stages involved in case-file analysis. Most of the samples in forensic chemistry are inorganic in nature, whereas, other FSL disciplines analyze organic or biological components which need biochemistry, molecular biology and biotechnology principles to perform the analytical processes. This is almost exclusively confined to 
the forensic fields that have experienced significant technological advances such as those in DNA analysis case-files. The largest increase in demand has been witnessed in forensic DNA analysis where such kind of processes has always affected the customers especially when the results are delayed.

\subsection{Comparison of Case-File Backlogs in Different Laboratory Disciplines}

\subsubsection{Time Series of Weekly Backlogs}

The number of backlogged cases in forensic science laboratories changes daily among each discipline. When different laboratory disciplines are to be compared, the data collection starts at point $\mathrm{D}$ and ends at point $\mathrm{J}$ in Figure 2. New forensic evidence is submitted weekly while older cases are closed every day. Because the number is constantly changing, estimates of the number of backlogged cases are always difficult. This study presents in details a new technique for weekly backlog data collection and analysis, time series of which are shown in Figure 11 for the three laboratory disciplines. The results show that in forensic toxicology laboratory, the number of weekly backlogged are lowest, where investigators submit very

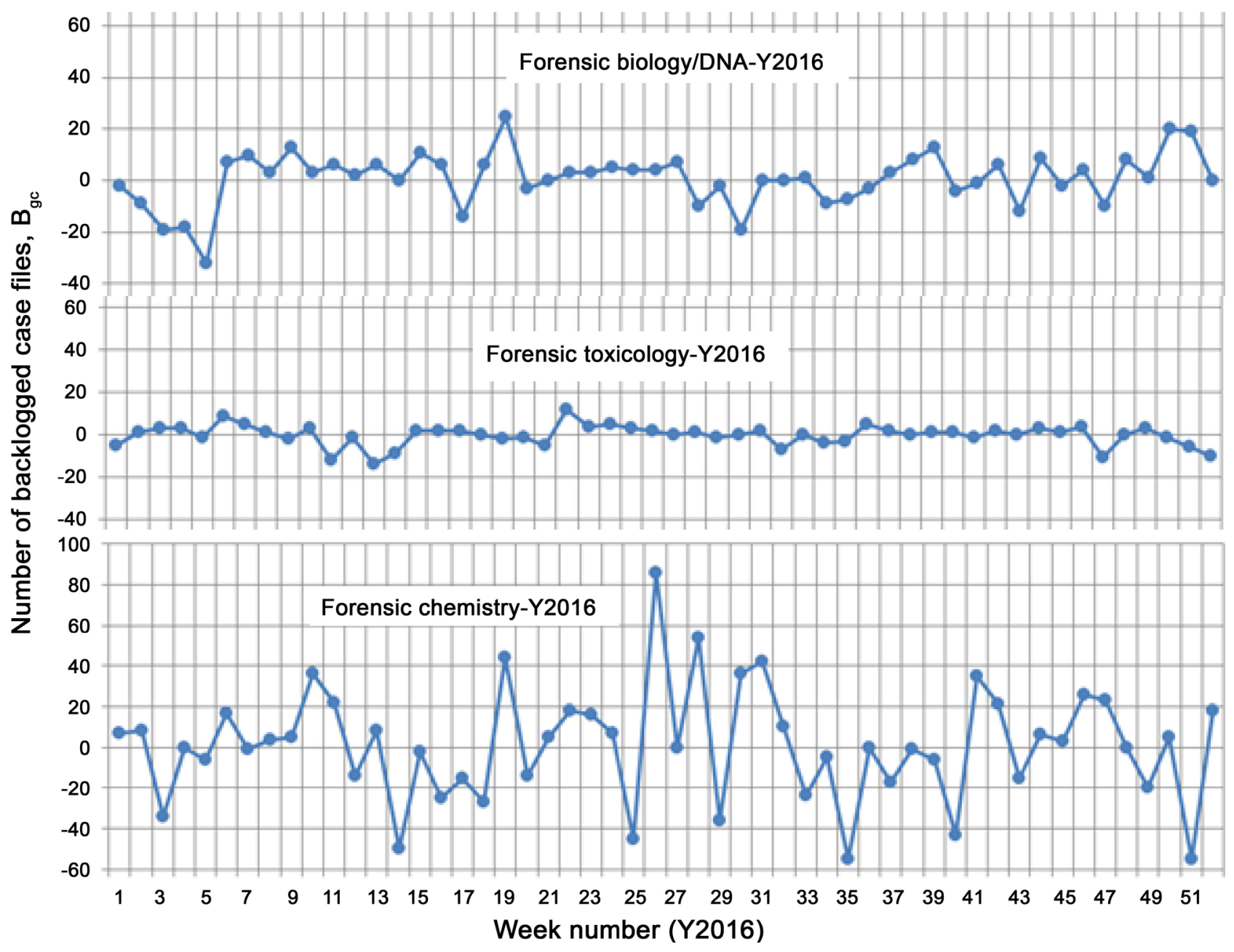

Figure 11. Time series of weekly backlogged case-files from different laboratory disciplines. 
few forensic evidence cases for analysis. Due to few case-files received and reported for forensic toxicology, the difference, $B_{g c}$ is small leading to lower numbers of backlogged case-files throughout the year.

This is not the case in forensic chemistry laboratory, which receive large numbers of case-files, reporting in large numbers, but $B_{g c}$ is of high magnitude both positive and negative. The negative $B_{g c}$ values indicate that the laboratory has been struggling for completing old cases most of the time, hence, highest the negative backlog. Thus, the forensic chemistry can be categorized as having strong positive and negative fluctuations in $B_{g c}$. This is observed in Figure 11 for cases of forensic chemistry laboratory which shows highest positive and negative backlog values.

Forensic biology/DNA laboratory shows intermediate values of weekly backlogs between the other two laboratories. There are weeks where the values of $B_{g c}$ are higher and negative, due to case-file processing involving old cases (e.g., week $\# 5$ and \#30). This can be attributed to samples within the case-files being of low grade and quality also known as compromised samples. However, samples that have been completed instantly or within the client's charter statement are direct samples for paternity cases which do not require re-processing as they are mostly fresh samples and few in one case-file.

\subsubsection{Comparing Backlogs between Different FSL Disciplines}

Figure 12 shows that, forensic biology/DNA managed to reduce its backlog in the year 2016, attributable to extended working hours, whereby staff were allowed to work extra hours. This means, FSL spent extra funds to tackle backlog. This causes deficit to other activities within the forensic science following budget re-allocation. For the case of forensic toxicology, during the year 2014, the average value of 6.2 case-files backlogged per week was the highest for all laboratories, which decreased faster to -0.3 case-files per week in Y2016. This is due to

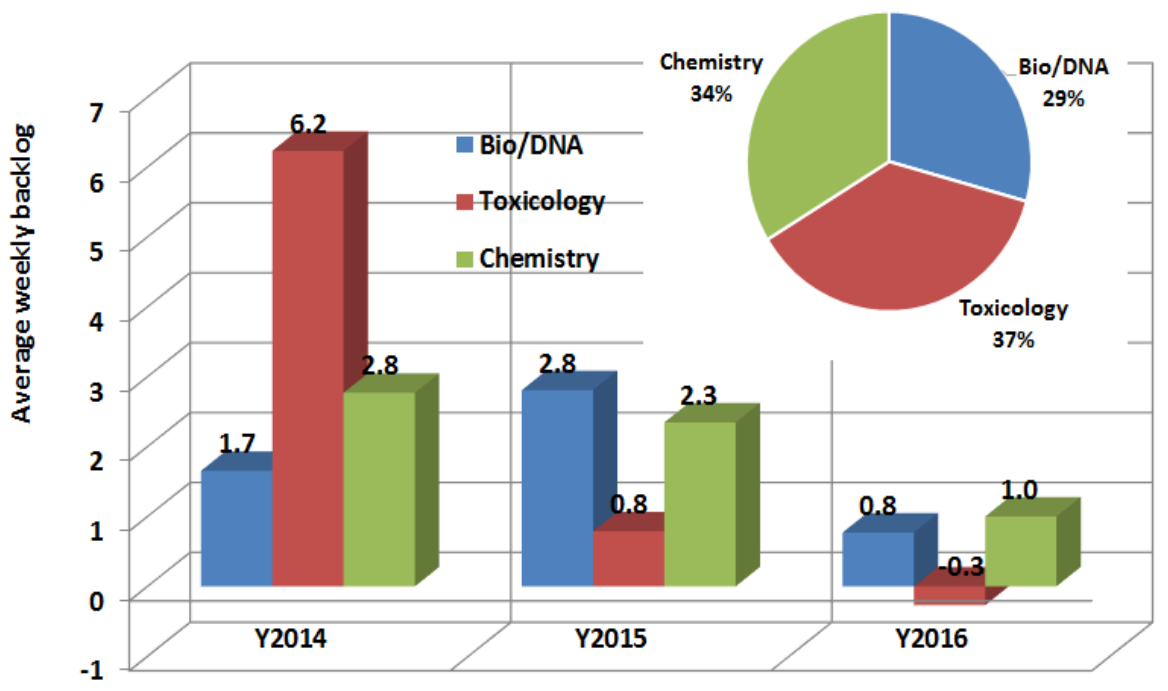

Figure 12. Average weekly case-file backlogs for the three FSL disciplines form 20114 to 2016. 
renovation of the laboratories. In the year 2016, the renovation has just been completed, leading to less casework being backlogged (which decreased to 0.8 and -0.3 case-files backlogged per week for Y2015 and Y2016, respectively). In the Y2016, the forensic toxicology was dealing with previous workload, leading to negative averaged backlog values. This may be contributed by the effort of training, outreach programs and awareness on the proper use of chemicals, especially industrial, agriculture and veterinary pesticides to the respective stakeholder, leading to reduced poisoning cases. Strict management, empowerment of regulatory systems and law enforcement on chemical safety, such as, Industrial and Consumer Chemicals (Control and Management) Act (ICCA) and Tanzania Pesticide Research Institute (TPRI) has contributed to the lowering of casework received in forensic toxicology laboratory.

For the case of forensic chemistry, this laboratory has managed to maintain low level of average weekly backlogs due to the fact that procedures within forensic chemistry laboratory are not complicated and advanced compared to the other two forensic science disciplines. However, given the large number of case-files received, the laboratory performance has also improved during the study period. The laboratory has also managed the processes within by eliminating the dead time, which is the time where case-files remain in stand still without being processed. As for forensic biology/DNA, this specific laboratory experiences variations in sample influx which causes fluctuation of backlog with the average of 1.7 (Y2014), 2.8 (Y2015) and 0.8 (Y2016) case-files per week. The values of average backlogged per week presented in Figure 12 are lower but manifest into large numbers in a month and also per year. However, significance technology changes have made the stakeholders to request for this type of analysis as it gives confirmatory results compared to speculations.

The pie chart inserted in Figure 12 shows the overall distribution of backlogged case-files among the FSL disciplines in the three-year period. Based on this distribution, it can be concluded that the backlog creation problem exist almost equally in the three laboratories. The pie chart shows also that the total number of backlogs was slightly higher in the toxicology laboratory (37\%) followed by forensic chemistry (34\%).

Furthermore, while Figure 10 shows that forensic chemistry has a low $B_{g c}$ at the end of the Y2016, Figure 12 presents high value of weekly backlogs in Y2016 compared to other laboratories. In spite of having both largest number of case-file influx (Figure 4 and Figure 5), also [22], the average backlogs per week are almost the same in Y2016 for forensic chemistry and forensic biology/DNA, that is, 1.0 and 0.8 case-files per week, respectively, indicating high performance in both forensic chemistry and biology/DNA laboratories.

It should be noted that, backlogs are related to workload for staff performing laboratory analysis [10] [12]. The backlog created in each laboratory per analyst in relation to the workload due to large number of case-files is shown in Figure 13. While Figure 6 shows the workload (case-files received per analyst per year), 


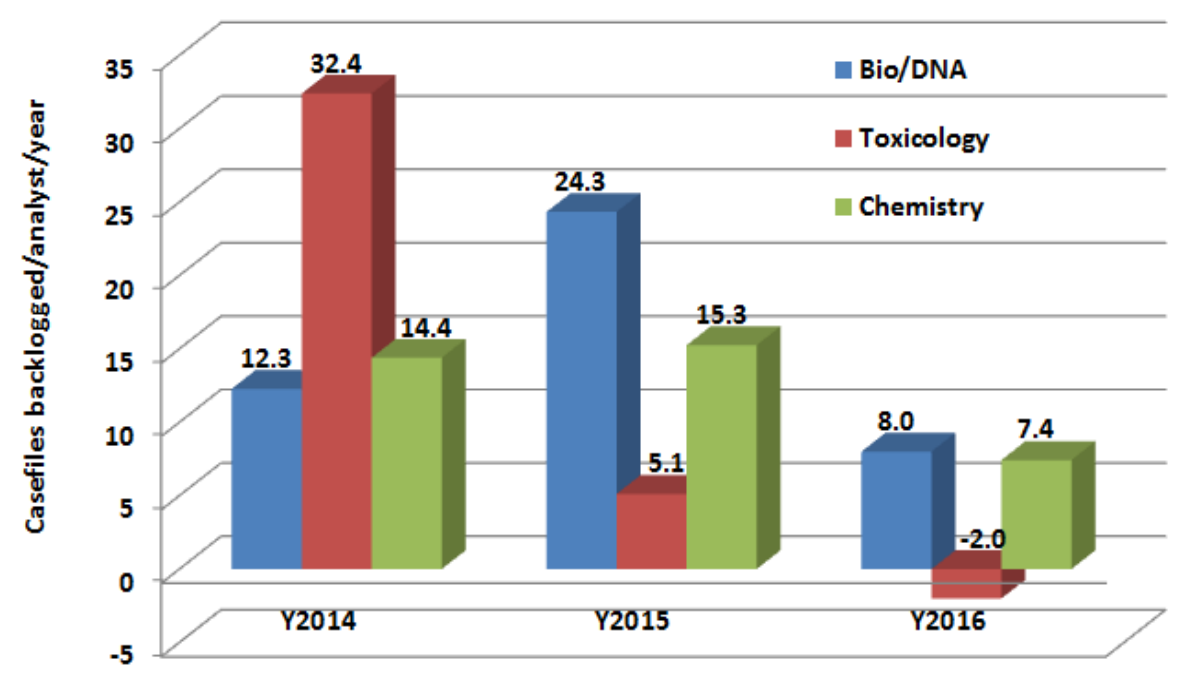

Figure 13. Case-files backlogged per analyst per year in different laboratory disciplines from Y2014 to Y2016.

Figure 13 shows the number of case-files backlogged per analyst per year. The difference between the two quantities is the case-files reported per analyst per year, presented in Figure 7.

Taking a case of forensic chemistry in Y2016, $N_{c r}=193.6$ case-files received per analyst per year, $N_{c p}=186.1$ case-files processed per analyst per year, yelds $B_{g c}=7.4$ case-files backlogged per analyst per year (as shown in Figure 13). It is thus important to address the problem of workload on analysts and support staff (attendants, SROs, registry etc.) if backlog are to be eliminated.

While biology/DNA analysis is generally requested in both criminal and civil cases, the demand and attention given to biology/DNA appears to exceed that of other forensic disciplines where case-files backlogged per analyst per year remained the highest in Y2015 and Y2016. Such public attention has resulted into complaints and criticism. Results presented in Figure 12 shows that more analysts were required in the Y2015 and Y2016 in forensic biology/DNA and chemistry, while a different case is depicted in Y2014. While re-allocation of staff to cover increased workload in some laboratories is inevitable, it creates instability of the workforce, necessitating creation of multi-professional laboratory analysts that could play similar roles in different laboratory disciplines.

In addition, it is in non-DNA disciplines that forensic laboratories expect demands to increase rather than remain constant or decrease. In the past, additional staff could not be added because of the space limitations imposed by the size of the laboratory facility. At the moment, the space exists but the funds and permits to hire additional forensic scientists are scarce. Virtually the FSL could use additional funding to hire more analysts to meet the increasing demand for services and reduce workload and backlogs. However, an increase in the number of available analysts alone will not solve all the problems associated with the increase in requests. Moreover, hiring additional analysts without hiring additional supervisors leads to an increase in inefficiency. This is because new employees at low- 
er entry levels require intensive supervision and it is difficult to get senior chemists in the labor market to fill supervisory posts in the FSL. Consequently, the study focused on identifying and elimination of bottle necks (as presented in Figure 1) so as to increase efficiency and hence competitiveness apart from obtaining funding to hire additional forensic scientists and supervisors. In this study, a number of possible ways to achieve this goal have been identified.

Based on the data on backlogs presented in Figure 12 and Figure 13, it is clear that the FSL is required to hire additional staff to meet the expectations of the stakeholders and the communities they serve as extended TAT results also from inadequate staff to process the incoming samples. However, no standards exist regarding the number of FSL analysts and supervisors necessary to meet the need of a particular community with a particular crime rate. To set such a standard in the future would require further research.

\subsection{Statistical Analysis of Weekly Backlog Data}

Statistical analysis was used to build an insight of the nature of case-file backlogs data series, in order to allow proper planning of backlog elimination in the FSL. Table 4 shows the statistical analysis of backlog data in forensic science laboratories for Y2016. Results show that the values of standard deviation for $B_{g c}$ data differ among the laboratories that is, forensic chemistry $(\sigma=28.01)$, toxicology $(\sigma=4.92)$, and biology/DNA $(\sigma=10.28)$. The $B_{g c}$ data from forensic chemistry laboratory has the highest standard deviation, meaning that on weekly basis the laboratory shows strong fluctuations in the backlogs compared to other laboratories. A high standard deviation shows that the backlog data is widely spread (less predictable) since the laboratory receives large numbers of case-files, attached with legal pressure from the clients, but due to fewer analysts, backlogs are continuously generated.

The backlog data for forensic biology/DNA shows high standard deviation of 10.28, next to forensic chemistry indicating strong fluctuations. This is due to the fact that high abrupt demand for cases which require forensic testing exist from time to time. In 2016, the number of case-files increased as well as sample influx, with each sample having a report that carries its own weight. This is different from other laboratories such as environmental management, food and drugs testing where few samples are received. While Figure 10 shows fluctuation

Table 4. Statistical analysis of the case-files received, reported and backlogged on weekly basis $(N=52)$ for Y2016.

\begin{tabular}{ccccccccccc}
\hline Parameter & \multicolumn{3}{c}{ Case-files received $\left(D_{c}, N_{c r}\right)$} & \multicolumn{2}{c}{ Case-files reported $\left(J_{c}, N_{c p}\right)$} & \multicolumn{3}{c}{ Case-files backlogged, $B_{g c}$} \\
\hline FSL Discipline & Bio/DNA & Toxicology & Chemistry & Bio/DNA & Toxicology & Chemistry & Bio/DNA & Toxicology & Chemistry \\
\hline Mean & 7.60 & 3.12 & 26.06 & 6.83 & 3.38 & 25.06 & 0.77 & -0.27 & 1.00 \\
Std. Deviation & 4.98 & 2.46 & 17.53 & 8.93 & 4.36 & 22.70 & 10.28 & 4.92 & 28.01 \\
Skewness & 1.74 & 1.30 & 0.70 & 1.97 & 1.71 & 0.52 & -0.60 & -0.73 & 0.24 \\
Kurtosis & 4.16 & 2.65 & 1.18 & 4.54 & 2.14 & -0.81 & 1.51 & 1.38 & 0.83 \\
\hline
\end{tabular}


with highest magnitude in $B_{g c}$ for forensic chemistry, Table 4 shows that the weekly average values are comparable to those of forensic biology/DNA, due to high negative and positive backlogs. Results show also that backlogs data have stronger fluctuations than both $N_{c r}$ and $N_{c p}$ data for all laboratories. The $B_{g c}$ data, however, shows lower values of skewness (closer to zero) compared to $N_{c r}$ and $N_{c p}$, indicating distributions closer to a normal distribution.

Statistical analysis was further conducted by using PDFs of weekly backlogs data for forensic chemistry. The statistics on annual drug test request submissions and the corresponding backlogs are currently very high. Drug seizures have occupied a substantial share of laboratory work in the FSL. Increased number of requests for drug test is an observed challenge to the FSL management. Requests for the analysis of drug seizures constitute approximately half of the total volume of forensic requests submitted to FSL laboratories annually in the GCLA. Although drug seizures account for the largest share of forensic workload (compared with toxicology, biology/DNA analysis, and other requests), the process of identifying controlled substances is not as time-consuming as other forensic functions.

Figure 14 presents the PDF of weekly backlog data for forensic chemistry for three consecutive years. Results differ widely between the three consecutive years (Y2014, Y2015 and Y2016). The values of $B_{g c}$ were more uniform and concentrated near zero for the year 2014 with a peak at $B_{g c}=5$ case files backlogged per week. In Y2015, however, two peaks were observed in the PDF indicating that two or more factors were affecting the backlogs. The peak for Bgc $<0$ can be attributed to increased effort on backlog elimination by processing older case-files, whereas, the peak at $B_{g c}>0$ indicates frequent generation of new backlogs in the laboratory. During Y2016, the values were spread to the left (up to -60 case-files

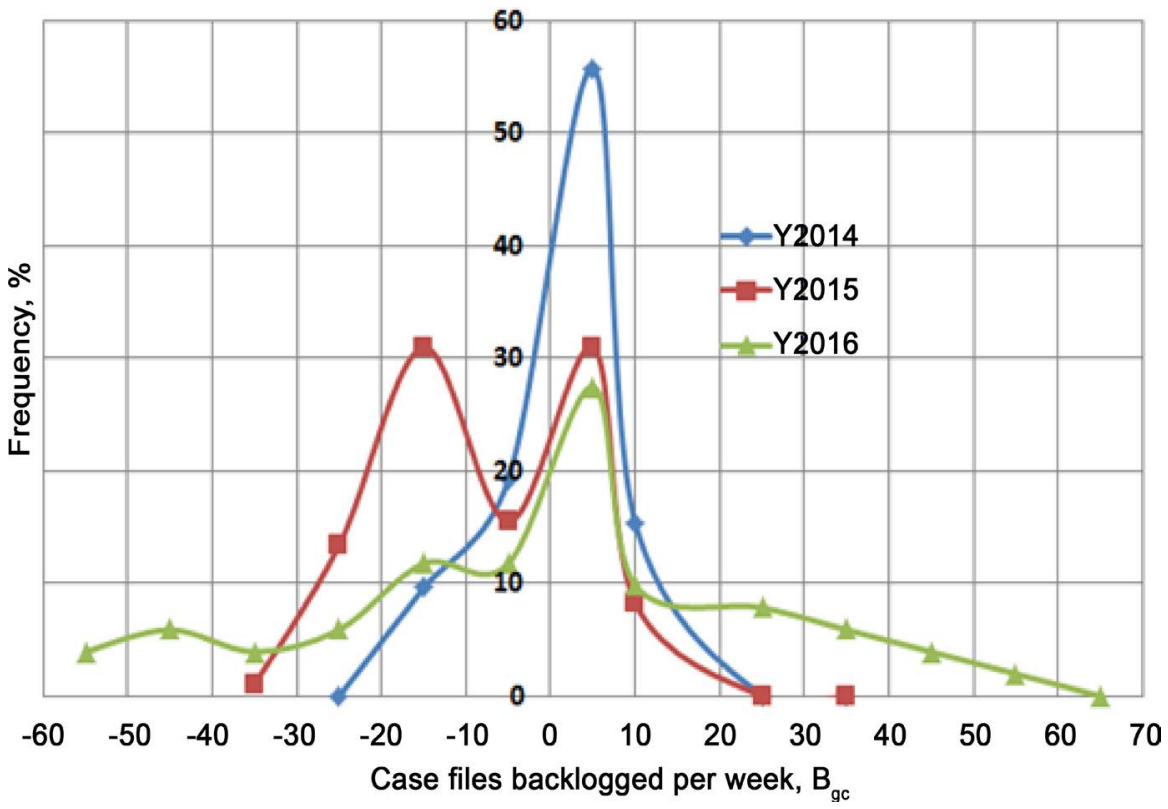

Figure 14. Probability density functions for the case-file backlog data from forensic chemistry laboratory. 
per week) and to the right (up to 65 case-files per week). The extent of laboratory backlogs is indicated by the spread of backlog data on the right and left hand sides of the PDF. This shows that, more case-files were backlogged per week in the year 2016, indicated by wider spread of backlog values with long tails on both sides. The spread of $B_{g c}$ data up to -60 case-files per week indicates that efforts for eliminating old backlogs were effective, processing up to 60 old case-files per week. On the other hand, there was high generation of new backlogs up to 65 case-files per week. That is, this year the laboratory did not perform well in terms of creation of backlogs, due to several reasons, including overwhelming number of case-files, large number of samples per case-file, managers spending days in attending court sessions, renovation of the working areas, etc. The large number of negative backlog values for 2016 means files received in previous week were being processed together with case-files received in the same week, which leads to extended TAT.

In Y2015, the weekly backlog data shows bi-modal behavior (two peaks on either side of the vertical axis), at $B_{g c}=5$ and -15 case-files per week, respectively. This shows that there were two dominant phenomena existing in the laboratory, which are creation of new weekly backlogs at low rate (peak on positive side) and elimination of existing or old backlogs at high rate (peak on negative side). For the years 2016 and 2014, the single peaks were on the side of new backlogs created in the laboratory at around $B_{g c}=5$ case-files per week.

Figure 15 shows the CDFs of the weekly backlog data for the three consecutive years. Cumulative distribution function (CDF) of backlogged case-file data, $B_{g c}$ (a real valued variable) is the probability of that $B_{g c}$ will take a value less than or equal to $x$. The wide span of $B_{g c}$ values in Y2016 indicates that there were more backlogs created in Y2016 than in the previous years $\left(B_{g c}>0\right)$ and also more of the formerly backlogged case files were processed $\left(B_{g c}<0\right)$. Results show that up to 65 case-files were backlogged per week in 2016, while up to 55 old backlogged case-files were processed and reported per week. The $B_{g c}$ were the lowest in Y2014 with narrow span of $B_{g c}$ values within 10 case-files per week. The larger negative value of $B_{g c}$ in Y2014 than the positive values, indicates that more of the old backlogged case-files were processed than new backlogs were generated. The behavior of CDF for forensic chemistry was similar for all years except the span of $B_{g c}$ values, which changed from one year to another, indicating the extent of the backlogs problem. As shown in both Figure 14 and Figure 15, backlogs grow in magnitude (indicated by span of $B_{g c}$ data) due to increasing demand for FSL services, but on average, the number of case-files backlogged decreases with time (Figure 12). The probability of not finding a backlogged case-file $\left(B_{g c}=0\right)$ for forensic chemistry is low between $(35 \%-50 \%)$ for all the three years. The probability of finding less than 10 backlogged case-files per week was $13 \%$ and $4 \%$ for Y2016 and Y2014, respectively, while there was no chance of finding $B_{g c}<$ 10 in Y2015.

To compare the dynamics of backlog creation in the FSL, PDFs were used to analyze data from different laboratory disciplines and years, as shown in Figure 16. 


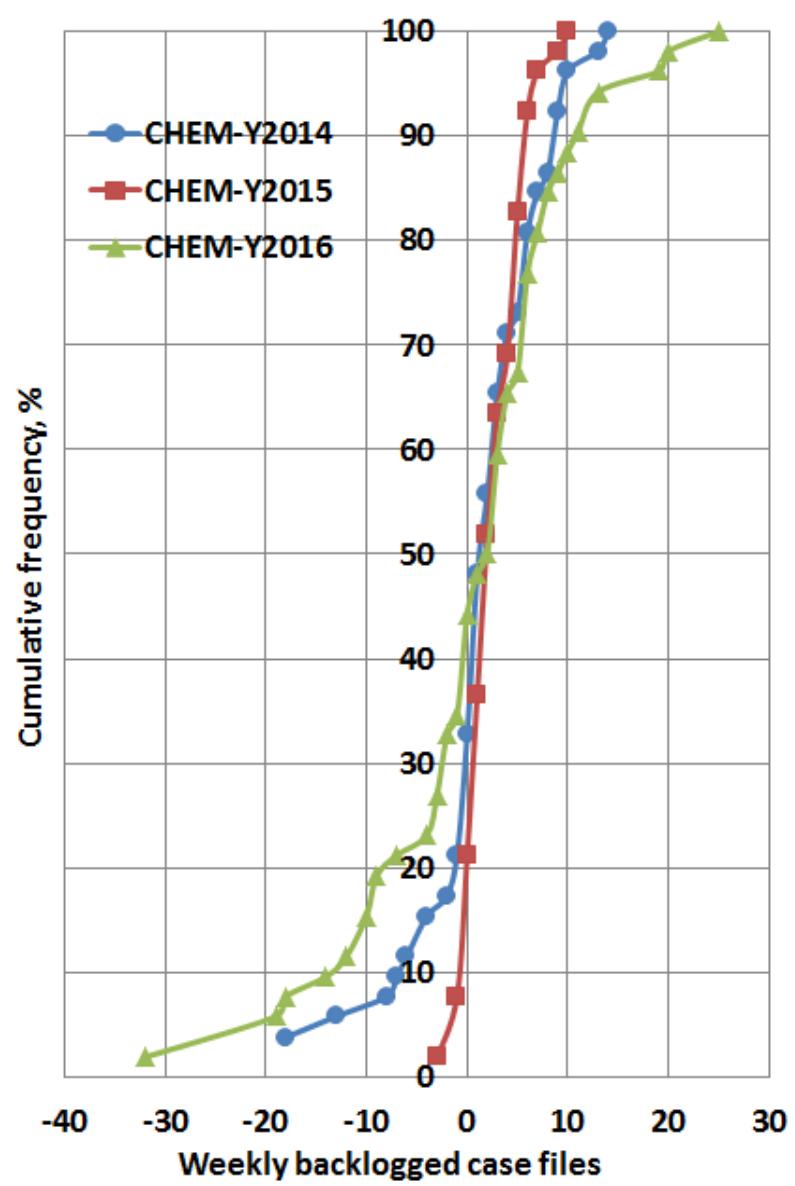

Figure 15. Plots of cumulative probability functions for weekly backlogged case-files in forensic chemistry laboratory for three consecutive years.

The PDFs are characterized by horizontal location of the peaks (values of $B_{g c}$ with highest frequency), span or range of $B_{g c}$ values and the shape in general.

Differences in the three aspects indicate that different factors affect the dynamics of backlog creation in these laboratories at different times. For DNA laboratory, the PDFs are of the same shape with same peak location at $B_{g c}=5$ case-files per week for the three consecutive years, while there was a shift in peak location from case-files per week $=-5$ to 5 case-files per week and changing shape of PDFs for toxicology between Y2014 and Y2016. The characteristics of the PDFs for Forensic chemistry laboratory were described thoroughly in Figure 14.

Figure 17 shows the cumulative functions of weekly backlogs for the three laboratory disciplines from Y2014 to Y2016. Due to presence of positive $B_{g c}$ values, for all laboratories, it is evident that there was a generation of new weekly backlogs for all laboratories. The extent of backlog creation (positive values of $B_{g c}$ ) was greatest for forensic chemistry and toxicology. For the case of forensic toxicology laboratory, this can be attributed to poor quality of samples submitted and also to the lack of sophisticated equipment (a problem which was solved in Y2016 via acquisition of the LC-MS-MS. 


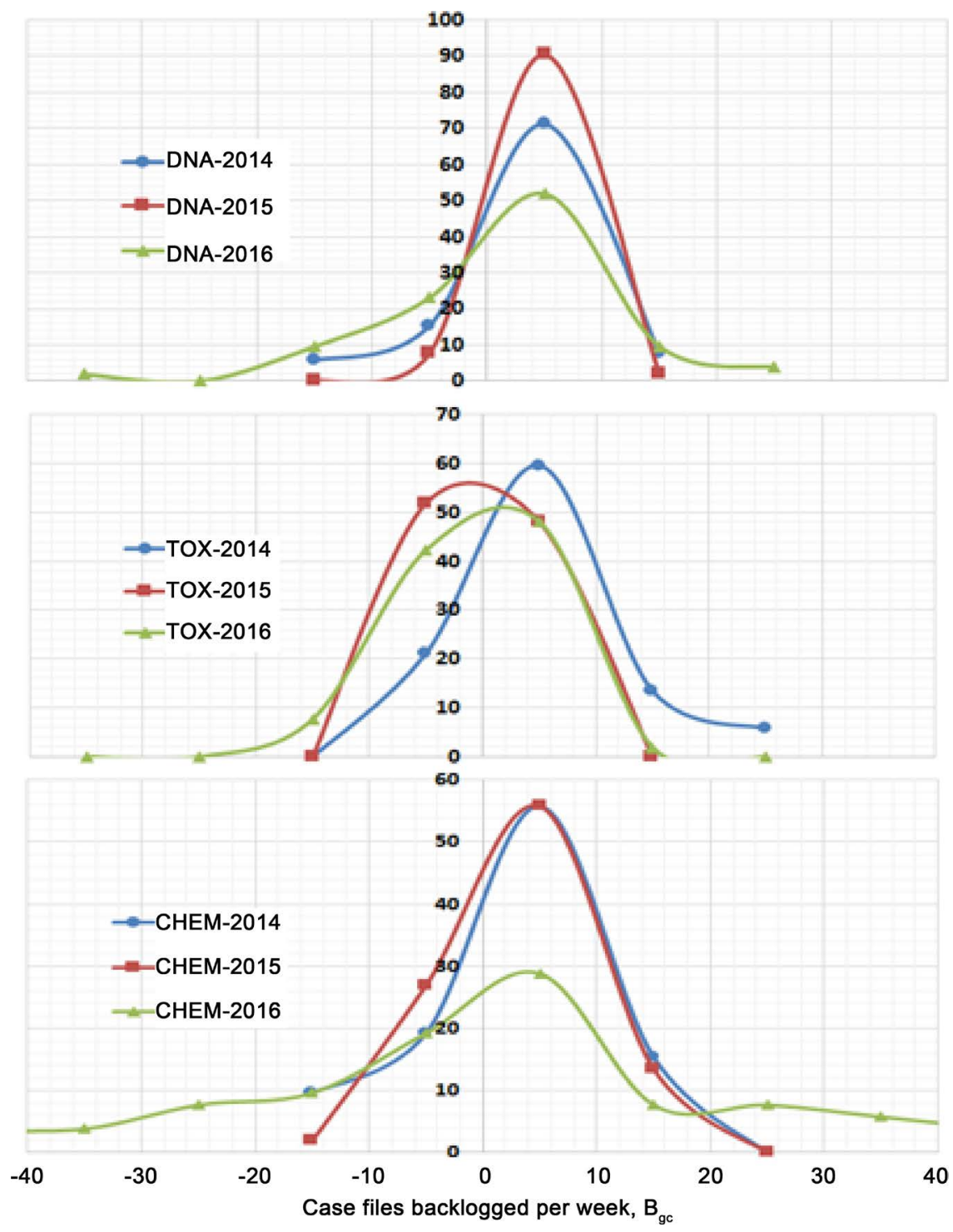

Figure 16. Probability density functions of the number of case-files backlogged per week for the three forensic science laboratories in three consecutive years.

Figure 17 shows that the probability of finding new backlogged case-file $\left(B_{g c}>\right.$ 0 ) for all laboratories in Y2016 was observed to be 55\%, while it was high at 70\% for the both Y015 and Y2015. This shows also that backlogs creation decreased towards Y2016.as depicted also in Figure 12. On the other hand, negative values of $B_{g c}$ indicates backlog elimination efforts in all the three FSLs. Forensic toxicology had the least effort in Y2016 and none of the efforts were observed in the preceding years. Forensic biology/DNA had a moderate effort followed by forensic chemistry, for which elimination of backlog was more effective ( $B_{g c}$ values up to -60). In general, the extent of negative backlogs was higher in Y2016 compared to Y2014 and Y2015, due to increased effort in backlog elimination. Moreover, according to Figure 17, and specifically for Y2016, a large number of case-files were reported from the three laboratory disciplines including old case-files which have been backlogged in previous weeks. 


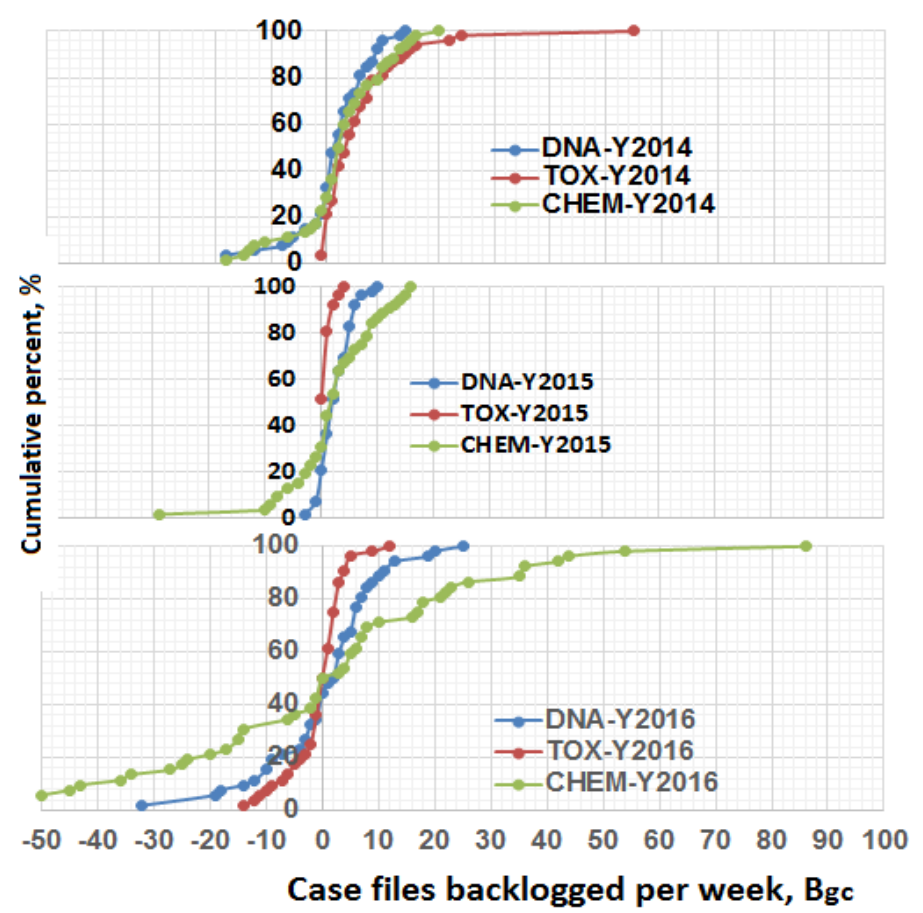

Figure 17. Cumulative probability functions for backlog data from different FSL laboratories for the three consecutive years.

\subsection{Fitting Probability Distribution Functions to Backlog Data}

Being a repeating measurement taken, the case-files backlog data from the FSL laboratories were further fitted with known probability functions in order to predict the nature phenomena of backlog creation on weekly basis using EasyFit software. This software provides the ranking of the fits that may lead to good predictions. Using sample data from forensic biology/DNA and forensic chemistry for the three consecutive years, the fitting results are summarized in Figure 18. While the fitted PDFs were similar in shape for forensic chemistry, there were changes in shape for forensic biology/DNA data, especially in Y2015. It is interesting to note also that all data sets for both forensic biology/DNA and chemistry laboratories were best fitted by Wakeby distribution, which is useful for describing flood flow data. This phenomenon fits well the concept of case-file backlogs which is the difference between incoming casefile $\left(N_{c r}\right)$ and outgoing case-files $\left(N_{c p}\right)$, similar to floods in a river.

\subsection{General Discussion}

The effect of keeping case-files unattended is that samples within the case-file may lose original form if not stored in the right condition. Also, the high number of backlogged cases for FSL leads to complaints from the judiciary. The effect of this is that judges and magistrates cannot keep up with the piling number of cases and thus hearings and determination of a substantial number of cases is postponed. Sometimes backlogs are caused by the investigators who submit samples that are of low quality or not admissible for laboratory analysis. In addition, for 

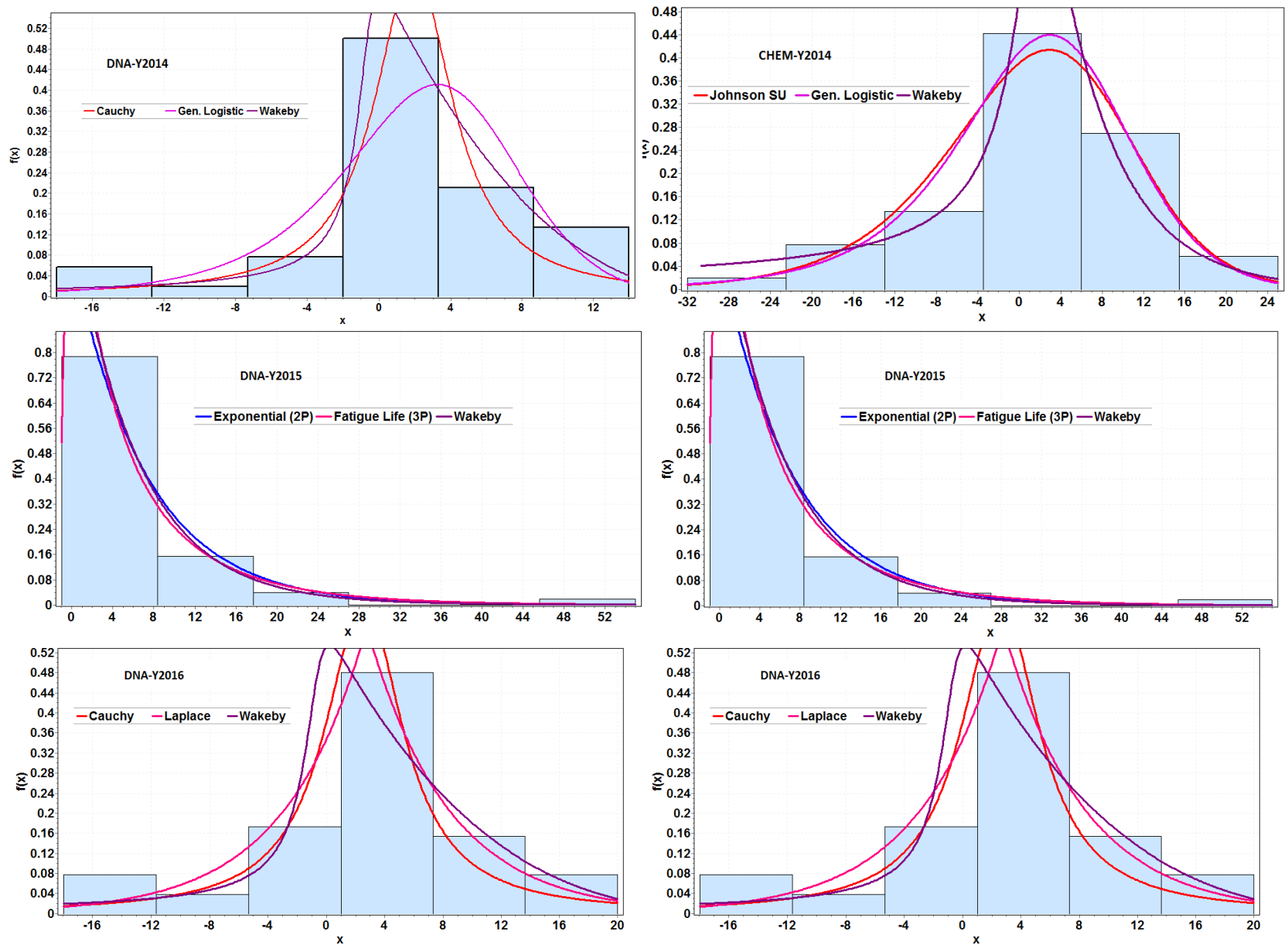

Figure 18. Fitting probability distribution to backlog data from forensic chemistry and DNA for Y2015 and Y2016.

the case of forensic chemistry, since most of the samples analyzed are associated with the drugs of abuse, most cases are filed under certificate of urgency which calls for a strategy of fast clearing the case-files. In addition such cases do not have a prolonged $\mathrm{TAT}_{2}$ (turnaround time for sample analysis) as most of its samples do not contain biological material which could have made the process complicated.

Automated case management systems with shared accessibility like LIMS, although costly, would greatly improve communication between FSL and stakeholders. Furthermore, backlogs and extended TAT result from the fact laboratory analysts often spend considerable time in the halls of courthouses waiting to testify. Judges must understand the cost to the community of this waiting time and improve communication.

The study has explored whether workload demands in FSL are being prioritized properly and whether there are important workload issues not being addressed. In this study, forensic biology/DNA and toxicology were most often identified as disciplines where requests exceed staffing capabilities.

One of the most commonly identified causes of a laboratory's inability to handle all requests is failure of the stakeholders to understand the limitations of forensic 
science and, including proper recognition of evidence that may be probative, the different types of analyses that may be conducted on an item of evidence, and a realistic view of what the results can and cannot show. This is because, once the samples or exhibits are submitted, they are counted and recorded before they can be rejected, building up on count and hence regarded as unprocessed cases or backlogs.

Better communication between stakeholders and forensic laboratories is an important factor in eliminating backlogs. Some of the workload issues identified in this study stem from a lack of communication with investigating officers and state attorneys. For example, forensic laboratories are often not told when defendants have pleaded guilty or that prosecutors have decided not to prosecute a case. Thus, forensic laboratories waste time analyzing evidence on cases that have been adjudicated. Laboratories are also not told that narcotics "stings" or task forces are being contemplated so that the laboratory can prepare for the increased workload. In some instances, officials initiate campaigns without prior identification of financial and human resource capabilities. Furthermore, forensic laboratories are often asked to handle "rush requests". These requests tend to disrupt the day-to-day operations of the laboratory, as the FSL has to re-adjustor reorganize to cope with abrupt demands.

Several suggestions to remedy problems associated with lack of communication include the laboratory to hire someone with experience in both forensic science and law enforcement to act as a liaison. Another solution is for the laboratory's director or a supervisor to have monthly meetings with the state attorneys and law enforcement agencies in order to prioritize cases. Yet, another solution is an automated information sharing system, which has been suggested by the FSL to unite all Criminal Justice Forum (CFJ) member organizations. This sharing system is in the process of establishment in Tanzania.

As discussed at length in this study, forensic science laboratories need increased funding to keep up with the ever-growing demand for services. To this end, some laboratories have implemented programs that generate additional revenue and provide enhanced services for clients that can afford to pay the associated costs. Consolidation of services is another opportunity for backlog elimination via optimal use of equipment and human resources. Laboratory disciplines used infrequently like toxicology, environmental laboratory, food and drugs could be performed at one zonal laboratory, rather than having each FSL maintain the staff and equipment to handle the occasional requests. Consolidation should only be considered, however, for disciplines that are rarely used and where analysts require a great deal of training to perform the required analysis. Trace evidence analysis and document examination are possible disciplines that could be performed by regional forensic laboratories.

Limit on the number of items tested is a policy that has been used in some laboratories to eliminate backlogs. Some laboratories impose limits on the number of items that can be tested in one case, for instance, the famous "three item rule". 
This rule may increase casework efficiency and cause investigators to take greater care in making laboratory requests and in identifying which items of evidence should be tested. Presumably, investigators are more likely to communicate with the laboratory in determining which items should be tested.

\section{Conclusions}

Statistics indicate that forensic chemistry laboratory has largest number of case-files received than any other FSL. In spite that the total number of case-files received in each of the five FSL is almost equal to the total number of case-files reported (processed) on annual basis, the high efficiency and performance of the backlog still exist. When compared to other years, Y2016 shows the highest case-files received per week and per analyst per year into forensic chemistry compared to forensic biology/DNA and toxicology whereas, the lowest number of case-files received per analyst per year was observed in forensic toxicology in all the three years studied.

The highest case-files reported per week and per analyst per year were also observed in forensic chemistry for the year 2016 while the lowest number of case-files reported per week and per analyst per year was observed in forensic toxicology in all the three years studied. Furthermore, the percentage of backlogged case-files for different laboratories in GCLA for Y2016 was observed to be the Forensic toxicology.

For the purpose of monitoring and controlling laboratory processes and signaling when and where corrective actions are necessary, the time series technique was applied whereby weekly backlogged case-files from different laboratories were compared. The rest of the forensic science laboratory discipline forensic biology/DNA and toxicology had constant fluctuation which was closer to the mid-line (average). While forensic toxicology has highest annual backlog rate of $29 \%$, the weekly backlog rate was $0.27 \%$ on average, due to the fewer case-files submission rate per week.

When comparing backlogging per analyst, the highest case-file backlogged per analyst per year was observed in forensic toxicology and forensic biology/DNA for the year 2014 and Y2015 respectively. However, the highest values of backlogged case-file on weekly basis (where $N=52$ ) were observed in forensic chemistry where the standard deviation and mean values were highest compared to other disciplines of forensic science laboratories for the Y2016. Also, according to the probability density function for the case-file backlog data it was observed that the highest positive backlogs occurred in Y2016 for forensic chemistry. Each year the backlog data shows different characteristics, leading to different shapes of PDFs.

The trend of increasing weekly backlogged case-files in forensic chemistry discipline was observed from 2014 to 2016 as revealed by widening of $S$-shaped cumulative probability function curves. Even though the weekly backlogs data for DNA and chemistry are evenly distributed on both sides of $N_{b c}=0$, Toxicology data are highly skewed to the positive side, indicating that new backlogs are continuously created with least effort of elimination on weekly basis. 


\section{Acknowledgements}

The authors are grateful to the GCLA Management for financial support which enabled completion of this study. Special thanks to the laboratory managers of forensic chemistry, forensic biology/DNA and Forensic Toxicology Laboratories for their support during data collection (Elias Mulima, Fidelis Segumba and Dominc Dominician). The support from the staff in the Sample Receiving Office (SRO) is also highly appreciated.

\section{References}

[1] Bashinski, J. (2010) DNA Laboratory Monthly Statistics, Sacramento, California, Office of the Attorney General, California Department of Justice. http://ag.ca.gov/bfs/pdf/Monthly.pdf

[2] CCLRTF (2009) California Crime Laboratory Review Task Force. Hertzberg-Davis Forensic Science Center, Los Angeles.

[3] Coble, M.D. and Butler, J.M. (2005) Characterization of New MiniSTR Loci to Aid Analysis of Degraded DNA. Journal of Forensic Science, 50, 43-53. https://doi.org/10.1520/JFS2004216

[4] Davis, K. (2010) Not All Rape Kits Must Be Tested, Laboratory Chief Says. San Diego Union-Tribune.

http://www.signonsandiego.com/news/2009/dec/12/not-all-rape-kits-must-be-teste d-lab-chief-says/

[5] Delisi, M., Hochstetler, A., Scherer, A.M., Purhmann, A. and Mark, B.T. (2008) The Stark Weather Syndrome: Exploring Criminal History Antecedents of Homicidal Crime Sprees. Criminal Justice Studies, 21, 37-47. https://doi.org/10.1080/14786010801972670

[6] Durose, M.R. (2008) Census of Publicly Funded Crime Forensic Crime Laboratories, 2005. US Department of Justice, Bureau of Justice Statistics Bulletin, Washington DC.

[7] Feist, A., Ashe, J., Lawrence, J., McPhee, D. and Wilson, R. (2007) Investigating and Detecting Recorded Offences of Rape. Home Office, London. https://doi.org/10.1037/e468392008-001

[8] Foullla, J., Mathies, C., Disley E. and Steinberg, P. (2010) Towards a Comparison of DNA Profiling and Databases in the United States and England. Land Center on Quality Policing, Technical Report.

[9] Hurst, L. and Lothridge, K. (2010) DNA Evidence and Offender Analysis Measurement: DNA Backlogs, Capacity, and Funding. US Department of Justice, Washington DC. http://www.ncjrs.gov/pdffiles1/nij/grants/230328.pdf

[10] Kara, V. and Skender, L. (2000) Drugs of Abuse in Urine. Archives of Industrial Hygiene and Toxicology, 51, 389-400.

[11] Lovrich, N.P., Gaffney, M.J., Pratt, T.C., Johnson, C.L., Asplen, C.H., Hurst L.H. and Schellberg, T.M. (2004) National Forensic DNA Study Report: Final Report. Washington State University, Division of Governmental Studies and Services, Pullman, Document 203970. http://www.ncjrs.gov/pdffiles1/nij/grants/203970.pdf

[12] Manyele, S.V. (2017) Optimization of Evidence Analysis Cost Using Arbitrary Re-Sampling Techniques for Sample Influx into Forensic Science Laboratory. Engineering, 9, 457-481. https://doi.org/10.4236/eng.2017.95027

[13] Nelson, M. (2011) Making some of DNA Backlog in 2010-myths vs, Reality. Special 
Report, US-Department of Justice, National Institute of Justice (NIJ), Washington DC. http://www.ojp.usdoj.gov/mj

[14] NFLIS (2013) National Forensic Laboratory Information System, Virginia, USA. US Department of Justice, Washington DC.

[15] NFLIS (2014) National Forensic Laboratory Information System, U.S. Drug Enforcement Administration, Office of Diversion Control, 2013 NFLIS Survey of Crime Laboratory Drug Chemistry Sections. U.S. Drug Enforcement Administration, Springfield.

[16] Peterson, J.L. and Hickman, M.J. (2005) Census of Publicly Funded Forensic Crime Laboratories, 2002. Bureau of Justice Statistics Bulletin, Washington DC. https://doi.org/10.1037/e311432005-001

[17] Pratt, T.C., Gaffney, M.J., Lovrich N.P. and Johnson, C.L. (2006) This Isn't CSI: Estimating the National Backlog of Forensic DNA Cases and the Barriers Associated with Case Processing. Criminal Justice Policy Review, 17, 32-47. https://doi.org/10.1177/0887403405278815

[18] Rubin, J. and Winton, R. (2009) L.A. Announces Plan to Reduce Backlog of Unexamined DNA Evidence from Violent Crimes. Los Angeles Times. http://theenvelope.latimes.com/la-me-dna29-2008oct29,0,5391785.story

[19] Rubin, J. (2009) LAPD to Expedite DNA Testing of Backlogged Rape Kits. Los Angeles Times. http://articles.latimes.com/2009/feb/10/local/me-dna10

[20] Rubin, J. (2009) Wider Scope of Backlog in L.A. County Sheriff's DNA Testing Is Revealed. Los Angeles Times. http://articles.latimes.com/2009/jan/28/local/me-dnamissed28

[21] Strom, K.J. and Hickman, M.J. (2010) Unanalyzed Evidence in Law-Enforcement Agencies: A National Examination of Forensic Processing in Police Departments. Criminology and Public Policy, 9, 381-404. https://doi.org/10.1111/j.1745-9133.2010.00635.x

[22] Tassoni, G., Cippitelli, M., Ottaviani, G., Froldi, R. and Cingolani, M. (2016) Detection of Cannabinoids by ELISA and GC-MS Methods in a Hair Sample Previously Used to Detect Other Drugs of Abuse. Journal of Analytical Toxicology, 40, 408-413. https://doi.org/10.1093/jat/bkv120

[23] Twohey, M. (2010) Illinois Plans Reforms for Processing DNA. Chicago Tribune. http://www.chicagobreakingnews.com/2010/02/illinois-plans-reforms-for-processin g-dna.html

[24] UDOJ, US Department of Justice (2020) Review of the Federal Bureau of Investigation Laboratory's Forensic DNA Case Backlog. Office of the Inspector General, Report 10-39. 